Article

\title{
Foodsheds and City Region Food Systems in Two West African Cities
}

\author{
Hanna Karg 1,* , Pay Drechsel ${ }^{2}$, Edmund K. Akoto-Danso ${ }^{3}$, Rüdiger Glaser ${ }^{1}$, George Nyarko ${ }^{4}$ \\ and Andreas Buerkert ${ }^{3}$ \\ 1 Physical Geography, Institute of Environmental Social Sciences and Geography, University of Freiburg, \\ 79085 Freiburg, Germany; ruediger.glaser@geographie.uni-freiburg.de \\ 2 International Water Management Institute, Battaramulla 10120, Sri Lanka; p.drechsel@cgiar.org \\ 3 Organic Plant Production \& Agroecosystems Research in the Tropics and Subtropics, Universität Kassel, \\ 37213 Witzenhausen, Germany; kydanso07@yahoo.com (E.K.A.-D.); buerkert@uni-kassel.de (A.B.) \\ 4 Faculty of Agriculture, University for Development Studies, Tamale, Ghana; nyarko2uds@yahoo.com \\ * Correspondence: hanna.karg@geographie.uni-freiburg.de; Tel.: +49-761-2039128
}

Academic Editor: Han Wiskerke

Received: 17 August 2016; Accepted: 7 November 2016; Published: 25 November 2016

\begin{abstract}
In response to changing urban food systems, short supply chains have been advocated to meet urban food needs while building more sustainable urban food systems. Despite an increasing interest in urban food supply and the flows of food from production to consumption, there is a lack of empirical studies and methodologies which systematically analyse the actual proportion and nutritional significance of local and regional food supplied to urban markets. The aim of this empirical study therefore was to compare the geographical sources supplying food to the urban population ("foodsheds") in Tamale, Ghana and Ouagadougou, Burkina Faso, to record the supplied quantities and to assess the level of interaction between the sources and the respective city. The study was conducted over two years, covering the seasons of abundant and short supply, via traffic surveys on the access roads to the two cities, and in the Tamale markets, resulting altogether in more than 40,000 records of food flow. Results indicated that food sources were highly crop- and season-specific, ranging from one-dimensional to multi-dimensional foodsheds with diverse sources across seasons. Across the commodity-specific foodsheds, city region boundaries were established. Within the proposed city region a relatively large proportion of smallholders contributed to urban food supply, taking advantage of the proximity to urban markets. While food provided from within the city region offers certain place-based benefits, like the provision of fresh perishable crops, a larger geographical diversity of foodsheds appeared to enhance the resilience of urban food systems, such as against climate related production failures.
\end{abstract}

Keywords: urban food systems; foodsheds; city region food systems; food flows; urban food supply; spatial analysis; GIS mapping; climate change

\section{Introduction}

Despite major development efforts, food and nutrition security remains a grand challenge in many African countries. At the same time, urban populations continue to increase. West Africa is among the most urbanising sub-regions in Africa, and its urban population is expected to rise from $44.9 \%$ in 2011 to $65.7 \%$ in 2050 [1]. This is affecting the way urban areas supply their food and is changing urban food systems. Changes are not only driven by growing urban demand for food but also by the globalisation of food markets and changing diets towards more animal products and processed foods [2].

Some scholars and advocates have associated the change in urban food systems with negative effects such as rising food prices and high energy demand, further accelerating climate change [3,4]. 
In response, shorter food supply chains and more localised food systems at the city or community level have been advocated [5]. Food from local and regional sources is considered to be "a vital component of a transition to a more sustainable and more just food system" [3] (p. 3) as it may improve the economic viability of local communities, provide better nutrition through fresh produce, and strengthen consumer-producer relationships.

The "local food system" approach as opposed to the agro-industrial "conventional globalising food system" is based on a variety of movements and theories, such as "alternative agrofood networks" [6] (p. 24) and has its roots in the Anglophone-industrialised world [5,7,8]. While these countries are embedded to a greater extent in globalised food chains, developing countries are characterised by a larger degree of local and regional production [9]. According to Reardon (2016) [2], $80 \%-90 \%$ of food consumed in developing regions comes from domestic sources, and only a small share from imports.

In developing countries, despite the dominating local production, localised food production has been promoted in view of rapidly growing cities. Therefore, urban and peri-urban agriculture as a means to enhance food security and provide income to urban dwellers has received increasing attention in the past decade in both research and development [10-12]. Most recently, the focus has shifted to city region food systems (CRFS) as a holistic and integrative planning framework comprising urban, peri-urban and rural landscapes $[9,13]$.

Whether the supply of food from local sources is more sustainable than that from non-local sources has been a matter of debate. Hinrichs (2003) [14] questioned the local-global dichotomy and Born and Purcell (2006) [15] introduced the problem of falling into the "local trap", arguing that a local-scale food system is not inherently better than a national- or global-scale food system.

Therefore, diversifying food supply including local, regional, national and global food sources is increasingly seen as a means to enhance resilience of the food system [13]. Multiple sources of food may also entail multiple ways by which food reaches the city as well as multiple trading systems [16]. If the production of a crop fails in one location, for example, due to climatic disaster or major price changes, other sources can mitigate the shortage. For example, as a response to the price hike for cereals on international food markets in 2007-2008, governments in West Africa began to diversify food sources and increased their reliance on the domestic supply of staple food crops [17].

Given the diversity and complexity of geographical contexts, a "one size fits all" approach is very unlikely to solve problems related to sustainable food systems [18] (p. 186). Therefore, there is a need to understand and map so-called foodsheds, i.e., food flows from the source of production to consumption at the city level. From an understanding of current food flows, improved strategies towards enhancing the resilience and the sustainability of urban food systems may be developed.

However, surprisingly, only a few empirical studies have attempted to analyse which geographical areas feed urban centres. In recent case studies, conducted mainly in North America, foodsheds were conceptualised as the potential quantity of food that could be grown in the vicinity of cities, but not as real-world food flows from production to consumption [19-22].

In developing countries, empirical data on food flows at the city level are very limited. They include a study in Kesbewa, Sri Lanka that recorded the food flows supplying the urban population with products for their daily food basket based on a survey among traders and expert interviews [23]. The purpose of the study was to identify the potential of a more localised production. Mukui (2002) [24] recorded food inflows on markets in Nairobi from wholesalers to determine the relative contributions of urban and peri-urban agriculture, and of rural-to-urban food inflows. Drechsel et al. (2007) [25] looked into urban-rural food flows in West African cities (Accra, Kumasi, Tamale, and Ouagadougou) for the purpose of identifying the role of urban farming and the resource recovery potential from food waste. Their focus was on 23 commodities from urban, peri-urban, and rural production. The study was carried out in two seasons (lean, peak) and included market and consumer surveys. In all these studies, quantities of incoming food flows were based on information from traders; however, the share of the total number of traders per commodity remained unclear. 
In the first two studies mentioned, only one season was considered which yields an only limited picture given the likely high seasonal differences. Obtaining quantitative data by market surveys is challenging, in particular where decentralised market systems prevent cross-checking of counts and traders are reluctant to provide information.

In view of the above, our study aimed at capturing quantities as well as the spatial and temporal patterns of food flows supplying urban populations in West Africa. Study areas were the rapidly growing cities of Tamale in Ghana and Ouagadougou in Burkina Faso. Specifically, the aims of this paper are (1) to determine which geographical areas supply the urban population ("foodsheds"); (2) to assess the contribution of the respective city regions; and (3) to discuss possible policy implications for resilience of the urban food system.

\section{Description of the Study Sites}

Ouagadougou is the capital of Burkina Faso and Tamale the third largest city of Ghana and major administrative centre of the Northern Region. The cities differ in size, in their national administrative and economic importance and in their historical development, influenced by the colonial Francophone and Anglophone systems, respectively. However, as neighbouring countries they also share a common market basin [26], and are both facing rapid urban growth. Ouagadougou experienced a population increase of 400\% between 1985 and 2012, from 500,000 to almost 2 million today [27]. In Tamale, the urban population doubled on average every decade, increasing from 83,650 in 1970 to 371,350 in 2010 [28]. In recent years, urban population growth has accelerated, accounting for an annual growth of $3.8 \%$ in Ouagadougou and $4.5 \%$ in Tamale.

Both cities are located in the West African Savannah Region with a unimodal rainfall distribution, and a long dry season. Ouagadougou has an annual precipitation of $880 \mathrm{~mm}$ [25]. Despite a harsh climate with low and variable rainfall and its generally low productivity and subsistence-dominated character, Burkina Faso's agriculture sector generates a third of the country's gross domestic product (GDP) and employs $80 \%$ of the population [29]. Main cereals are maize (Zea mays L.), sorghum (Sorghum bicolor L.) and millet (Pennisetum glaucum L.) that are produced mainly in rain-fed agriculture (Figure 1). However, the country also has potential in the use of surface water and groundwater for irrigation out of which so far only $10 \%$ (26,760 ha) is exploited [30]. Livestock production is an important pillar of the Burkinabe economy, and the principal cash crop is cotton (Gossypium hirsutum L.) accounting for a large share of the country's export income followed by oilseeds such as sesame (Sesamum indicum L.), and cashew nut (Anacardium occidentale L.) [31]. Burkina Faso is vulnerable to external trade shocks due to its landlocked location and volatile world market prices that caused large drops in the price of cotton in the late 1990s and early 2000s [32]. Burkina Faso is one of the poorest countries in West Africa and despite improvements in its agriculture sector, more than 3.5 million people, roughly $20 \%$ of the population, are considered to be food-insecure [29].

Tamale is located in the Guinea Savannah with an average annual precipitation of $1033 \mathrm{~mm}$ [25]. Due to its north-south expansion, Ghana has a number of agroecological zones including tropical rainforests. While the northern part of the country is suitable for staple crop production, particularly maize, rice (Oryza sativa L.), yam (Dioscorea spp. L.), and pulses, the South also produces fruits and cocoa (Theobroma cacao L.) with the latter as the main cash crop accounting for 16\% (USD 246.7 million) of the total exports in 2001 [31]. Roots and tubers for household consumption are more common in Ghana as compared with Burkina Faso where sorghum and millet dominate (Figure 1). Crop production in the Northern Region as in Burkina Faso is highly seasonal and, apart from a few irrigation schemes, limited to the rainy season. Despite this, livelihoods in and around Tamale largely depend on agriculture and related marketing. Tamale is a trade hub located on the North-South route linking the production areas in the north with those of the country's south. In the urban areas, subsistence and commercial backyard gardening are similarly common [33]. While Ghana is considered a relatively wealthy country in West Africa, a strong South-North gradient can be observed. The Northern Region is among the three poorest ones in Ghana with a poverty rate of 52\% in 2005/2006 
and a high rate of malnutrition, with $30 \%$ of children under the age of five being stunted or chronically malnourished [34,35].

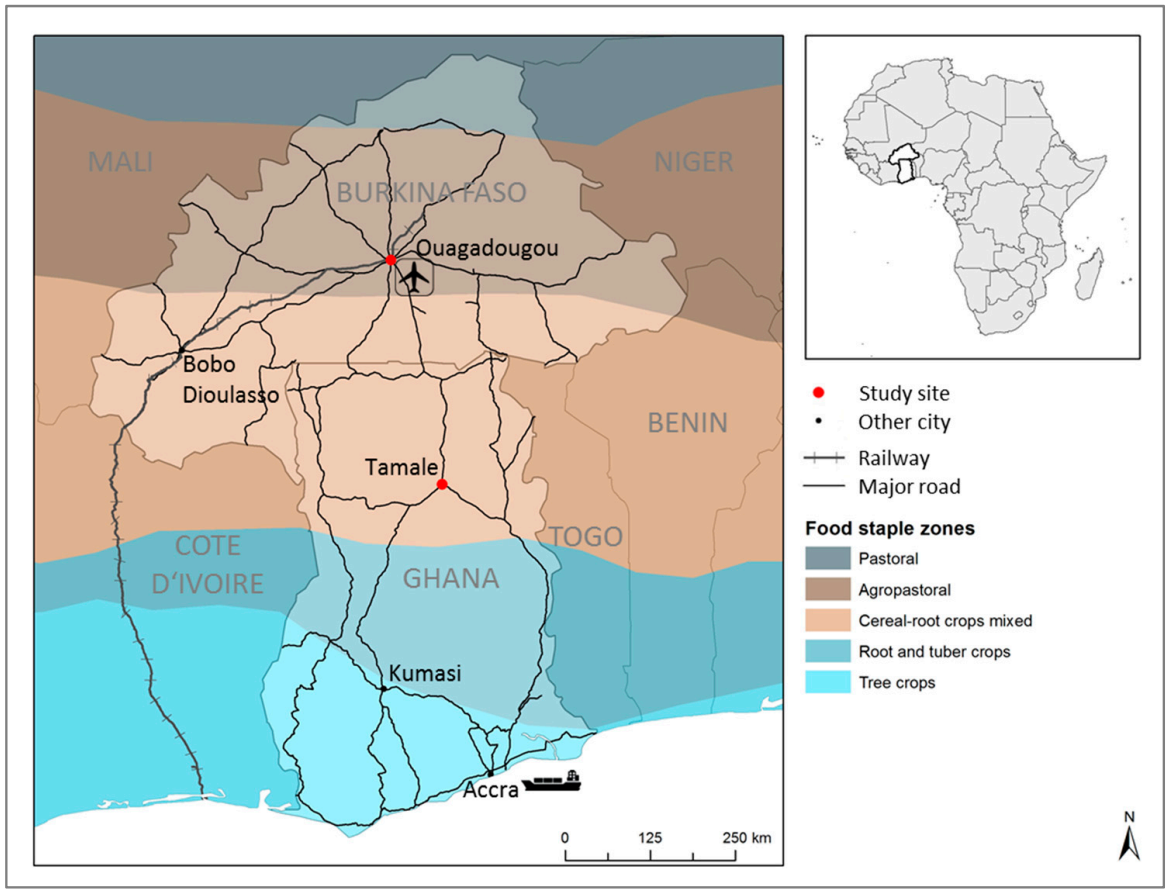

Figure 1. Location map showing the two study sites in West Africa and food staple zones (Modified after Auricht et al. 2014 [36]).

\section{Materials and Methods}

We applied a quantitative approach to assess flows of largely unprocessed food items that dominate consumption patterns in the study areas. More than 50 crops and animal products (live animals, meat) were captured, including slightly processed items such as smoked fish and processed rice (husked, milled) and groundnuts (unshelled). Eggs and dairy products were not considered.

The study comprised a road survey in both cities and a market survey in Tamale. Roads are the only entry point to Tamale. In Ouagadougou, food is also imported via railway from Côte d'Ivoire (Figure 1). While fresh food such as mango (Mangifera indica L.) is also exported from Ouagadougou via air, almost exclusively high-value processed food is imported by plane (personal communication with airport officials). Transport via waterways does not play a role for urban food supply in either city. The survey allowed recording virtually all the food entering the two urban areas via roads during the survey period. Thus, flows of food were recorded that would otherwise not be captured by official statistics or market surveys, such as food bypassing public marketplaces and reaching warehouses, restaurants or consumers directly. Secondary customs data were consulted to acquire further information on the origin of imported goods, i.e., to trace back the origin of goods coming from the port or a border town.

\section{Data Collection}

\subsection{Road Transport}

Flows of unprocessed food were captured on all primary and secondary access roads to the cities of Tamale and Ouagadougou (Figure 2). On these roads, all vehicles carrying food were recorded at official check points as they entered or left the city (Figure 3). The surveys were carried out with the help of enumerators who noted at each roadside (1) type of food item; (2) quantity; (3) source and (4) destination. 

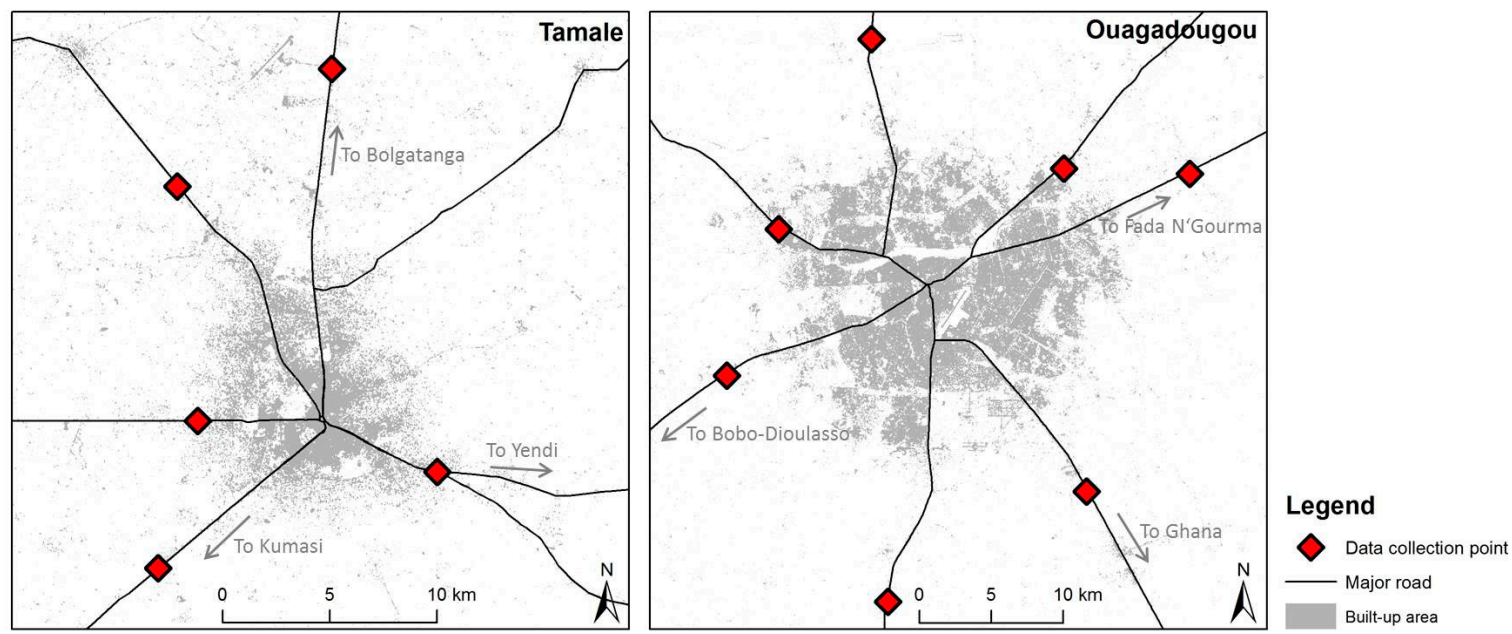

Figure 2. Locations of check points on the roads of the two West African study sites of Ouagadougou and Tamale.

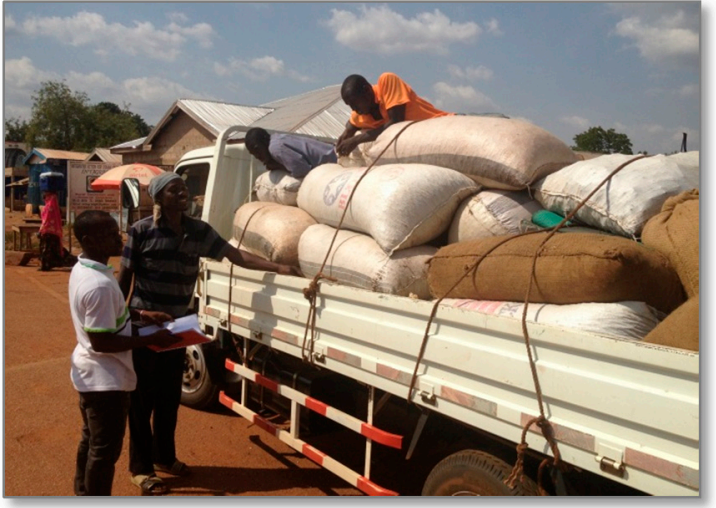

(a)

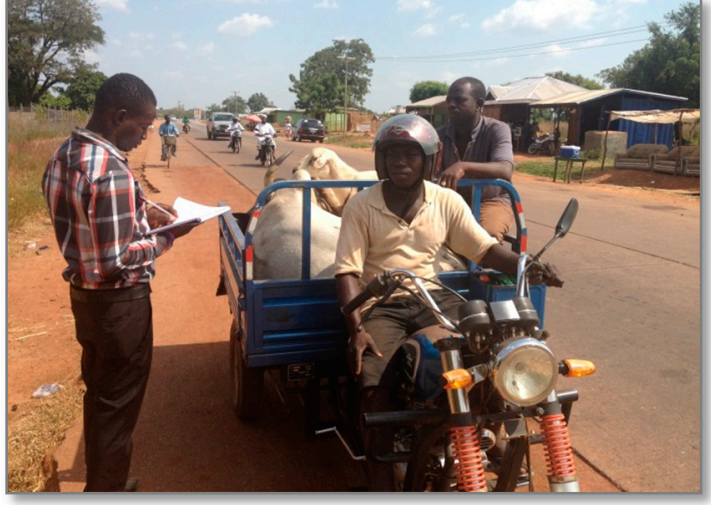

(b)

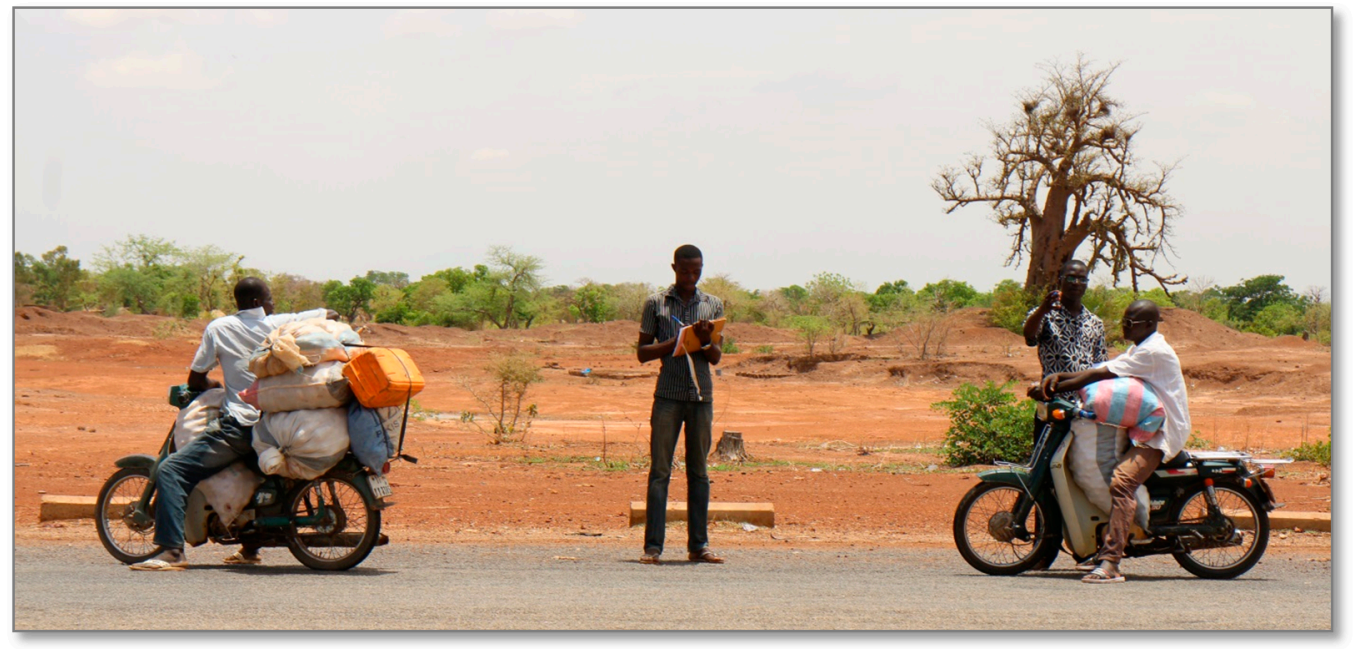

(c)

Figure 3. Data collection in the West African cities of Tamale (a,b) and Ouagadougou (c).

In Ouagadougou, enumerators were positioned at toll gates located on the seven access roads. Apart from one secondary road (Ouagadougou—Pabré) where data were collected $12 \mathrm{~h} /$ day, all other toll gates were covered $24 \mathrm{~h} /$ day. 
In Tamale, data were collected in collaboration with the police at existing road checkpoints located on the primary and secondary access roads outside the city entrance. The three primary roads were surveyed $24 \mathrm{~h} /$ day, while the two secondary roads with no major food flows during the night were covered $12 \mathrm{~h} /$ day.

Officers at these check points assisted in stopping the vehicles, and facilitated access to the driver or the driver's assistant. Vehicles that did not stop or where drivers were reluctant to give information were recorded as well and the quantity of food estimated where possible. Data were collected for the period of six days in each season, that is the peak production season (end of rainy season) and the lean season (end of dry season). The six-day period corresponds to the traditional market system in both regions (Box 1).

Box 1. Periodic Market Systems in West Africa.

Markets in the former kingdoms of Mossi (in central Burkina Faso) and Dagbon (northern Ghana) form an integrated, complementary system where markets at different hierarchical levels are held on different market days. This so-called periodic market system originated in pre-Islamic times and is found throughout West Africa [37]. In northern Ghana and central Burkina Faso, the market week usually lasts three or six days. This means, that every three or six days, local farmers have the opportunity to market their produce at the closest village or small town market. At these markets, traders purchase goods which they will typically resell at the next bigger (urban) market. In urban centres like Tamale and Ouagadougou, markets typically operate every day receiving goods from various village and small town markets as well as from nearby producers. In the case of Tamale, the main market with wholesale and retail functions has a specific market day, on which traded volumes and the food-supplying area increase considerably compared with the other week days.

In Tamale, the survey was carried out for two consecutive years and twice per season. In Ouagadougou, the survey was conducted in one year covering two seasons (Table 1).

Table 1. Metadata of the food flow surveys conducted in the West African cities of Ouagadougou (Burkina Faso) and Tamale (Ghana) between 2013 and 2015.

\begin{tabular}{|c|c|c|c|c|c|c|c|c|}
\hline & \multirow[b]{2}{*}{ Survey Periods } & \multirow[b]{2}{*}{ Season } & \multirow{2}{*}{$\begin{array}{c}\text { Total } \\
\text { Number } \\
\text { of Records }\end{array}$} & \multicolumn{3}{|c|}{ Missing Values (\%) } & \multirow{2}{*}{$\begin{array}{c}\text { Total } \\
\text { Incoming } \\
\text { Records }(\%)\end{array}$} & \multirow{2}{*}{$\begin{array}{c}\text { Incoming Records } \\
\text { with Urban } \\
\text { Destination }(\%)\end{array}$} \\
\hline & & & & $\begin{array}{c}\text { Quantity/ } \\
\text { Unit }\end{array}$ & Source & Destination & & \\
\hline \multirow{4}{*}{ Tamale } & 18-24 November 2013 & \multirow{2}{*}{ Peak } & \multirow{2}{*}{14,178} & \multirow{2}{*}{2.6} & \multirow{2}{*}{12.0} & \multirow{2}{*}{11.4} & \multirow{2}{*}{60.7} & \multirow{2}{*}{54.7} \\
\hline & 17-22 November 2014 & & & & & & & \\
\hline & 7-13 April 2014 & \multirow{2}{*}{ Lean } & \multirow{2}{*}{13,159} & \multirow{2}{*}{1.5} & \multirow{2}{*}{11.0} & \multirow{2}{*}{10.8} & \multirow{2}{*}{47.8} & \multirow{2}{*}{41.1} \\
\hline & 16-22 March 2015 & & & & & & & \\
\hline Ouagadougou & 1-6 December 2014 & Peak & 6834 & 0.6 & 28.6 & 28.2 & 67.4 & 44.2 \\
\hline
\end{tabular}

\subsection{Market Survey in Tamale}

At the main Tamale wholesale market, food inflows and outflows were recorded $24 \mathrm{~h} / \mathrm{day}$, in addition to the flows recorded on the road. In Ouagadougou, recording inflows and outflows at the market level was not feasible due to the decentralised market system. In Tamale, the market survey ensured a comprehensive picture by accounting for flows originating in particular from the north-eastern part of the country with small towns such as Gushegu and Karaga. The related tertiary road was not covered in the road survey due to the lack of a police check point. Moreover, on the market days of the immediate five village markets, the amount of food, loaded into vehicles leaving for Tamale, was noted. This improved the accuracy of the overall data. The road and market surveys complement each other, also for example for inner-urban food flows that could not be recorded on the roads. 


\subsection{Secondary Import and Export Data}

Official statistics on imported and exported food crops were obtained from the customs authority in Ouagadougou for the year 2014. These national-level data helped to identify the countries of origin when the border town or the next port was recorded as a source. For Tamale, aggregated national data were consulted for that purpose (FAOSTAT; UN Comtrade). Apart from the road survey, the only other entry point that was not covered by our study was the railway in Ouagadougou. Therefore, secondary data were acquired from the railway company SITARAIL based in Abidjan, Côte d'Ivoire, revealing the monthly quantities of goods imported via railway to Burkina Faso. Monthly quantities were adjusted to represent quantities imported during the period of six days. The airport as an entry point did not play a role for imported unprocessed food items.

\section{Data Processing}

Data were entered into a PostgreSQL database with PostGIS extension, capable of storing and processing large amounts of spatial data [38]. Processing and cleaning the data included the assignment of source and destination to georeferenced locations, standardising units, handling blanks and metadata. As in Tamale additional data were compiled through the market survey, thereafter duplicates were identified and removed before analysis. This was done on the basis of metadata such as date, time, direction and number plate. Measurements of weights and units were taken in the markets. Quantities were converted to fresh weight by assessing unit weight per transport volume (sacks, boxes, etc.).

Altogether, around 6000-7000 records of food flows were captured per survey (Table 1). One vehicle may refer to a single record or to several records if the vehicle carried different types of food or different units. Missing values related to quantity and unit for all observed flows, including those captured on the roads and in the market, were minor, representing $0.4 \%-2.6 \%$ of the data. In Tamale, source and destination were not recorded in about $10 \%$ of the cases. In Ouagadougou, the percentage was higher (see limitations). Incoming records represented between almost 50\%-67\% of the data after removing transiting vehicles and outgoing flows. Between one-third and half of the data contained information on the urban destination and were used for the foodshed analysis. In turn, in Tamale, about 6\% and in Ouagadougou about one-quarter of the incoming vehicles did not include specific information on the destination.

\section{Data Analysis}

\subsection{Mapping Urban "Foodsheds"}

Analogous to a watershed, the term "foodshed" is used to describe the flow of food in the food system from different sources to a particular end point (in this case the city). While the original term refers to the food system in general, today it often relates to local food systems connecting local producers and consumers [3]. In this paper, we use the term "foodshed" for the geographical sources supplying food to the urban population. To map urban foodsheds of different commodities and seasons, all records with an urban destination were extracted from the dataset. The urban boundary was based on the densely built-up area. Then, heat maps were created to visualise the sources of these flows on the basis of relative quantities. Unless stated otherwise, fresh weight was converted to percentages to allow for comparisons between commodities, regardless of their weight.

The quantification of incoming flows was based on fresh weight and included all incoming flows irrespective of their source. Major outgoing flows, i.e., food that was exported from the city for consumption elsewhere, were considered in the interpretation of results.

\subsection{Delineating City Regions}

The concept of city regions is not new but has been reintroduced as a relevant spatial unit in the context of urban food systems. The basic premise of a city region food system approach is that 
urban, peri-urban and nearby rural areas exist in a (non-linear) continuum with multiple types of food system-related flows and interactions [9]. The main interest of the approach is to tackle food-related challenges such as inadequate nutrition, and food waste by improving the connections between urban and rural areas (ibid.). Accordingly, the "territorial approach to food systems" links a "geographic space of analysis to a relevant geographic space of action" [39] (p. 3).

The geographic space of a city region in the context of food systems has not been defined based on comparable criteria but is considered "a flexible space constructed from meaningful linkages whether they be political, economic, cultural, physical or ecological" [9] (p. 30). However, in order to serve as a common analytical spatial unit, it is useful to at least conceptualize the extent of such a region, so as to assess the contribution of sources from the city region to the urban food supply. Therefore, we aimed at delineating the spatial extent of city region(s). We did that by taking a food system perspective including the nearby production of food (source) and the consumption of food in the city (destination).

Thus, data were collected at the city scale, but the foodshed analysis reached beyond the local level and even included international food sources. City regions form a subset of all foodsheds and encompass food sources from urban and peri-urban areas as well as from the nearby rural hinterland (Figure 4).

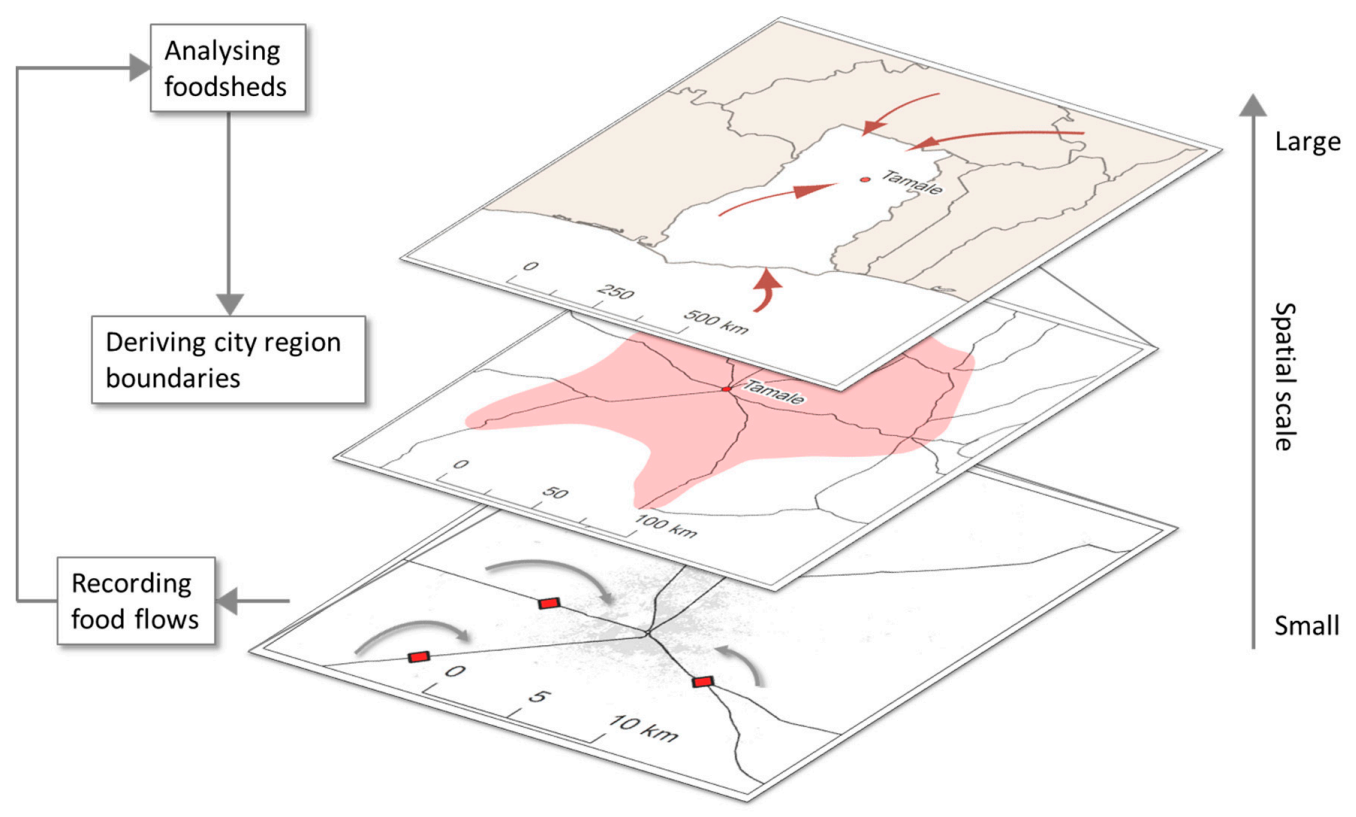

Figure 4. Spatial scale of data collection and analysis of foodsheds and city regions in Ouagadougou (Burkina Faso) and Tamale (Ghana).

The relevance of sources around the cities for urban food supply thereby determined the boundary setting. Given the magnitude of food items, they were grouped into clusters using common classifications schemes. Apart from the basic food groups suggested by FAO (1964) [40], we also considered household expenditure data as an alternative option given that a typical household spends about half of the income earned on food in both cities [41,42]. The approach covered $92 \%$ of the food urban dwellers pay for (apart from processed food and beverages/water) as documented in the World Bank consumption database which is based on national household surveys [43].

Thus, food items were included in the analysis on the basis of three different ways:

(1) All crops were considered (Figures 14 and 15).

(2) Based on absolute fresh weight, the most common crops in each food group were selected for each city [40] (Figures 14 and 15; Appendix Table A1). 
(3) The three to five highest-ranking food groups in terms of household expenditure were considered (Figures A1 and A2; Table A2).

In addition, the number of records was plotted on the distance gradient as a proxy for the number of vehicles entering the city.

\section{Limitations}

On the road, the passage of all vehicles apart from big passenger busses was recorded. In Ouagadougou, railway cargo goods were covered by official statistics provided by the railway company, but not goods hand-carried into the city by train passengers. Unlike in Tamale, in Ouagadougou, only goods coming from beyond the check points were noted down. Therefore urban production and some parts of peri-urban production were not considered.

During the first lean season survey in Ouagadougou, we were not permitted to work at the Ouagadougou-Loumbila toll gate (northeast of Ouagadougou). Therefore, vehicles and loads were recorded without interacting with the drivers. As a result, locations (source and destination) could not be recorded and food quantities were estimated by our enumerators based on a rigorous training. Supported by expert information, source locations were assigned to recorded flows based on the type of food and the type of vehicle.

Road surveys do not allow tracking down the exact location of production as drivers may not know these locations. However, we assumed that in general production-of perishable goods and basic staples in particular-took place close to the marketplace from where goods were transported to the city, and which, as the starting point of each journey, was recorded. In case of cities with major wholesale markets (e.g., Techiman, Ghana), ports or border towns being recorded as sources, secondary data helped tracking back the likely country of origin.

Having covered six days per season may, of course, not reflect the entire season well, also considering that seasonality varies by crop. The data were not extrapolated for the year as the aim of the study was not to quantify overall urban food supply such as done by Drechsel et al. (2007) [25] but to analyse food sources and foodsheds, and to compare urban supply within distinct periods. Additional information was gathered on likely events which could have affected food flows, to exclude factors such as droughts or flooding.

\section{Results and Discussion}

\section{Urban Foodsheds}

Both countries heavily rely on cereals as the main source of calories. In terms of weight, maize and rice were the most important cereals entering the cities, followed by millet, sorghum and wheat (Triticum aestivum L.; Figures 5 and 6). In Burkina Faso, millet, maize, and sorghum are the most important food commodities for household consumption [44]. While millet is the major staple for the most vulnerable households, sorghum and maize are consumed by the majority of households (ibid.). The relatively small incoming quantities of millet and sorghum as compared with maize and rice can be attributed to the fact that these crops are typical subsistence crops. While most of the maize was supplied by national sources, more than $90 \%$ of the rice was imported, out of which approximately $70 \%$ came from Côte d'Ivoire to Burkina Faso via railway as revealed by secondary data. It is, however, likely that rice imported via railway also supplies other urban centres along the route such as Bobo-Dioulasso. Therefore, the figure probably overestimates the quantity of imports and has to be treated with care. Elbehri (2013) [17] and FAOSTAT (2013) [45] reported smaller numbers at the national scale: According to FAOSTAT (2013) [45], the share of imports in relation to rice supply was about $60 \%$ for the year 2013. Elbehri (2013) [17] stated a decrease of the proportion of rice supply covered by domestic production from $70 \%$ in the mid-1990s to less than 30\% today. Another likely reason for the gap between our results and figures in the literature stems from the fact that imported rice 
is being transported mainly to the capital from where it is redistributed to other places in the country. Our data showed that more than $60 \%$ of the rice, likely most of it imported, left Ouagadougou again.

The resulting dependence on imports can be attributed to a rising consumption of rice particularly in urban centres and a relatively lower productivity [17]. According to our data, imported rice passed mainly through the neighbouring country of Côte d'Ivoire that has historically been the major transit route for exports from, and imports to, the landlocked country [32]. Smaller quantities also passed through Togo and Ghana.

As in Burkina Faso, in Ghana, rice is also associated with an urban diet, with per capita consumption of rice in urban areas accounting for about $76 \%$ of total rice consumption (CARD, 2010 cited by [46]). Ghana is also far from self-sufficient for rice, importing more than $50 \%$ of its domestic demand in 2013 [45], even though rice production has increased in the recent decade. Between 2003 and 2013, it has more than doubled from 238,810 to 569,524 tonnes. Although production takes place in all regions of the country, the Northern Region is a major production area providing almost $40 \%$ of the domestic supply [46]. The geographical proximity of production may be the reason for a higher level of self-sufficiency in Tamale as compared with the national average. According to our data, $14 \%-20 \%$ of the rice was imported in the lean and peak season, respectively. Other cereals-apart from wheat-were also produced in close vicinity to the city. Warehouses in the source communities ensure stable supply across seasons. Cereals, foremost maize, and also other staples such as yam, beans (Phaseolus vulgaris L.) and groundnut (Arachis hypogaea L.) were exported from Tamale to the central and southern parts of the country in both seasons. The importance of these staples for Tamale as compared with Ouagadougou becomes obvious when comparing the incoming quantities per capita (Figure A7).

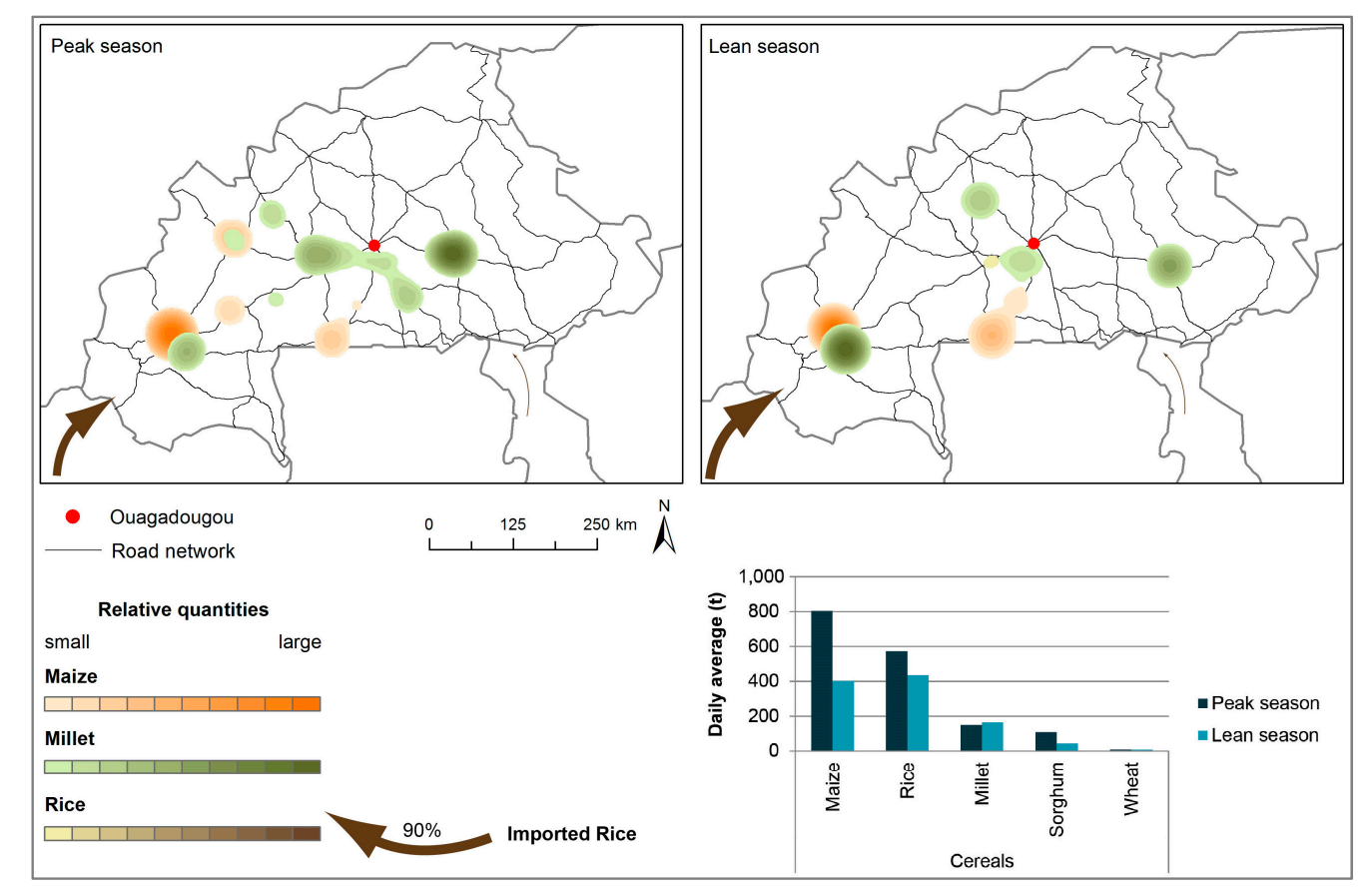

Figure 5. Seasonal cereal foodsheds for Ouagadougou (Burkina Faso) and daily incoming quantities (in metric tonnes). 


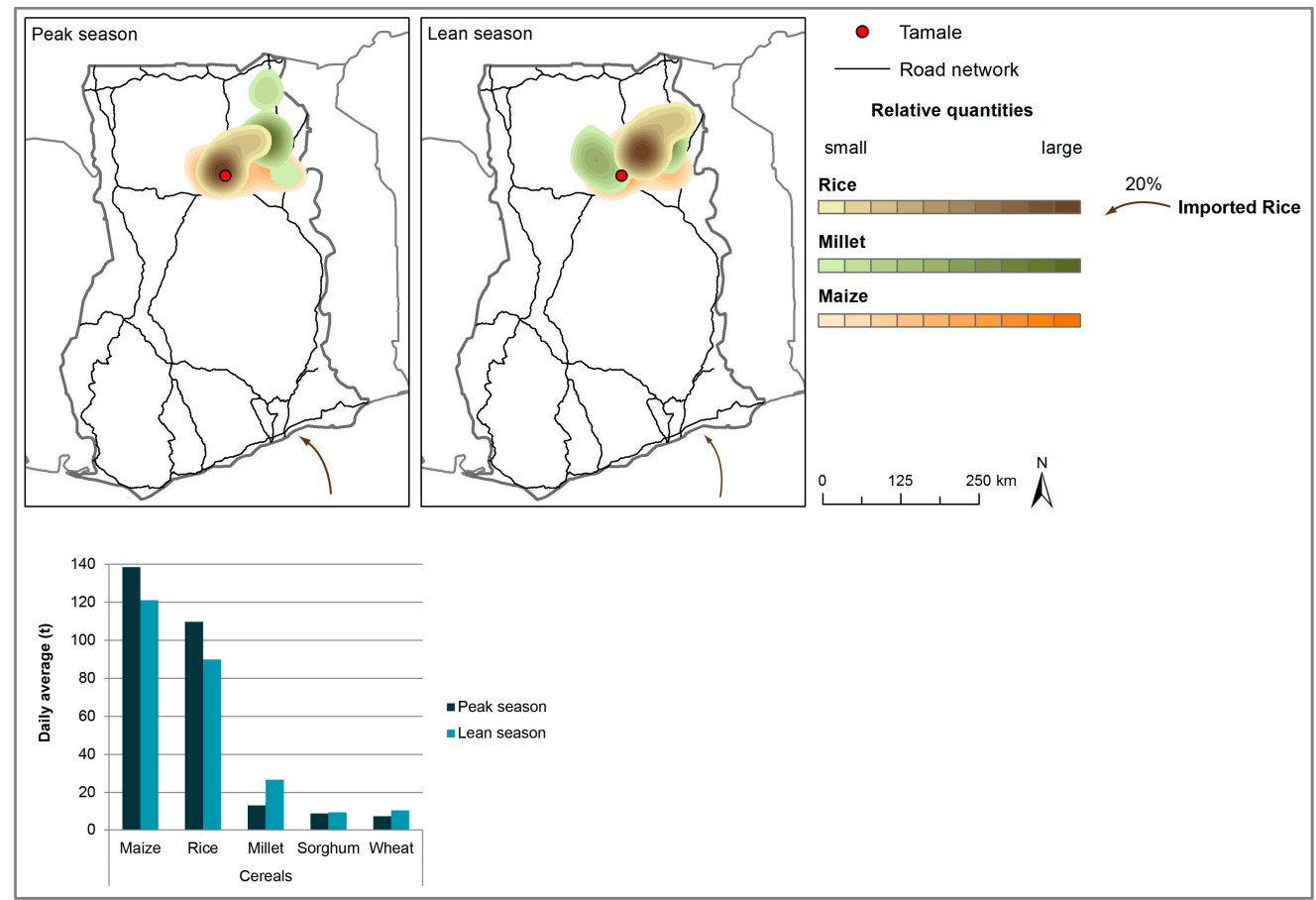

Figure 6. Seasonal cereal foodsheds for Tamale and daily incoming quantities (in metric tonnes).

For Ouagadougou, Bobo Dioulasso was a major supplier of maize (in both seasons) and millet (particularly in the lean season). The western part of the country is known as a surplus production area for cereals [47]. Apart from Bobo Dioulasso, millet also came from Pouytenga in the peak season and from Fada N'Gourma in the lean season. These towns are important wholesale markets, attracting produce from the millet surplus areas in the east (as confirmed by Haggblade et al., 2012 [26]), and facilitating cross-border trade. For instance, cereal trade flows between Burkina Faso, Ghana and Niger are directed through the large cross-border market in Pouytenga [48]. Our data confirmed that considerable quantities of maize left Ouagadougou for Niger, while millet was exported to coastal countries.

Cross-border trade in West Africa is considered to be far below its potential extent, considering the diversity of agroecological zones. This is due to high transaction costs caused by limited transport and communication infrastructures, fragmented regional markets and lack of predictable trade policies ([17]; Box 2). Even though ECOWAS was established to promote free trade, numerous barriers prevent translating the official commitment into practice [17].

Box 2. Transport Costs and Prices in West Africa.

In West Africa, there are manifold factors increasing transport costs and causing delays on the roads including slow and costly trade procedures and informal taxation at the borders [17]. According to OECD (2013) [49], transportation costs even exceed tariffs in cost and delays on border crossings; further, coordination problems and harassments significantly contribute to the total transport costs. As a response, the West Africa Trade Hub (WATH) project was funded to provide information on, and to fight, road harassment ([50]; Figure 7). The WATH project found that in Burkina Faso and Ghana there are, on average, five control points per $100 \mathrm{~km}$ and that the average amount of bribe cost per $100 \mathrm{~km}$ was USD38 for Burkina Faso and USD10 for Ghana. The average time spent at the control points per $100 \mathrm{~km}$ was $45 \mathrm{~min}$ for Burkina Faso and $35 \mathrm{~min}$ for Ghana [51]. That means that for a trip from Accra to Ouagadougou, drivers have to spend, on average, USD146 on informal payments, and have to spend more than 6 hours on more than 50 check points, the border not included.

In addition, cartels that control transport services charge high transport prices despite an aged vehicle fleet and poor services, resulting in far higher prices than in developed countries [52]. Thus, even if external measures are being taken such as lowering fuel prices to reduce transport costs, it would not have an impact on the price which is determined by the trucking market. 
Fish plays an important role in both the Burkinabe and Ghanaian diets and contributes to the necessary protein intake given the heavy reliance on staple crops [53]. In Burkina Faso, urban households spend $11 \%$ of all expenditure for (unprocessed) food on fish, while households in Ghana even spend almost one quarter of their food expenditure on fish (Table A2). Ghana is one of the few countries in the world where fish accounts for more than $50 \%$ of the population's animal protein intake as compared with the world average of $17 \%$ [53]. Therefore, it is not surprising that fish dominated the incoming animal sources in both cities (Figures 8 and 9). However, outgoing flows need to be considered, whereby in Ouagadougou up to $28 \%$ of the fish left the city again for other places in the country. In Ouagadougou, the greater part of the fish was imported from Senegal and Mali (dry fish) as well as from Ghana (fresh fish). However, since Ghana cannot meet its own fish demand by the domestic catch, it is likely that fish coming from Ghana had its origin elsewhere. National data show that currently, in Ghana, two-thirds of domestic consumption is covered by domestic supply, while one-third is met by imports [54]. One-quarter of the total domestic fish catch in Ghana is met by inland fishery (ibid.). According to UN Comtrade (2015) [55], the major exporting countries in 2015 were EU countries (50\%) and Togo (39\%). Our results revealed that in Tamale, $83 \%-87 \%$ of the supply passed through the port of Tema and a small proportion also originated from central Ghana.

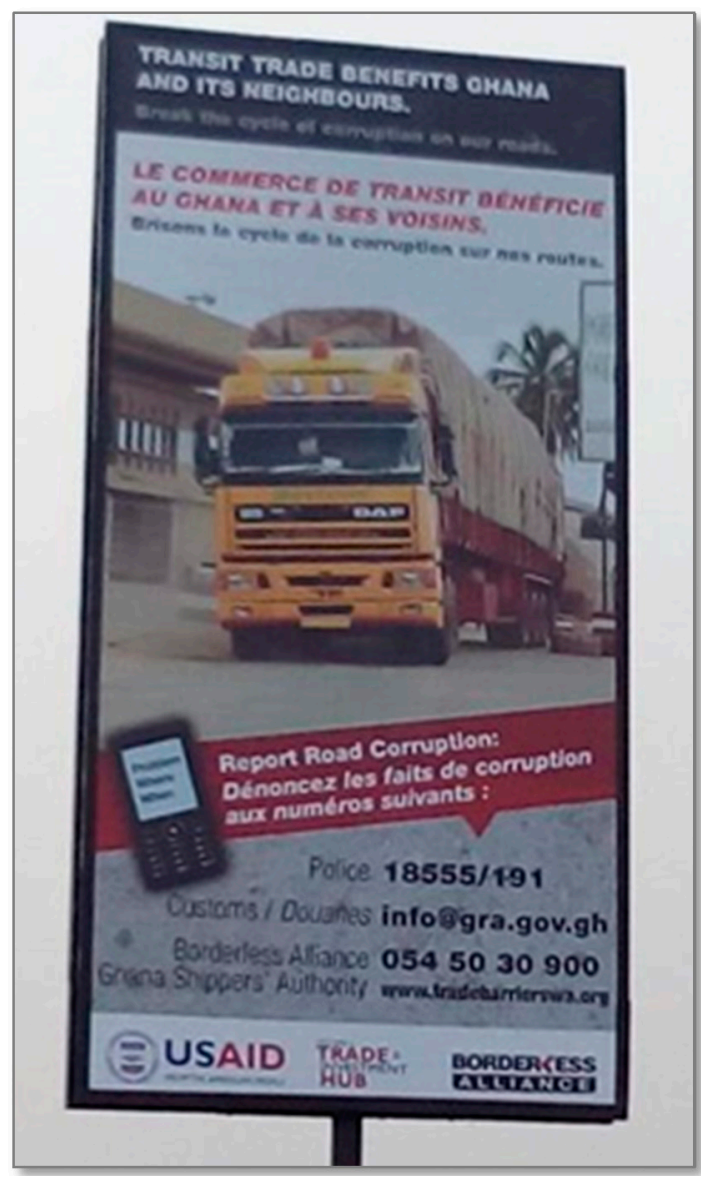

Figure 7. Billboard to fight corruption along the Tema-Ouagadougou highway [56]. 


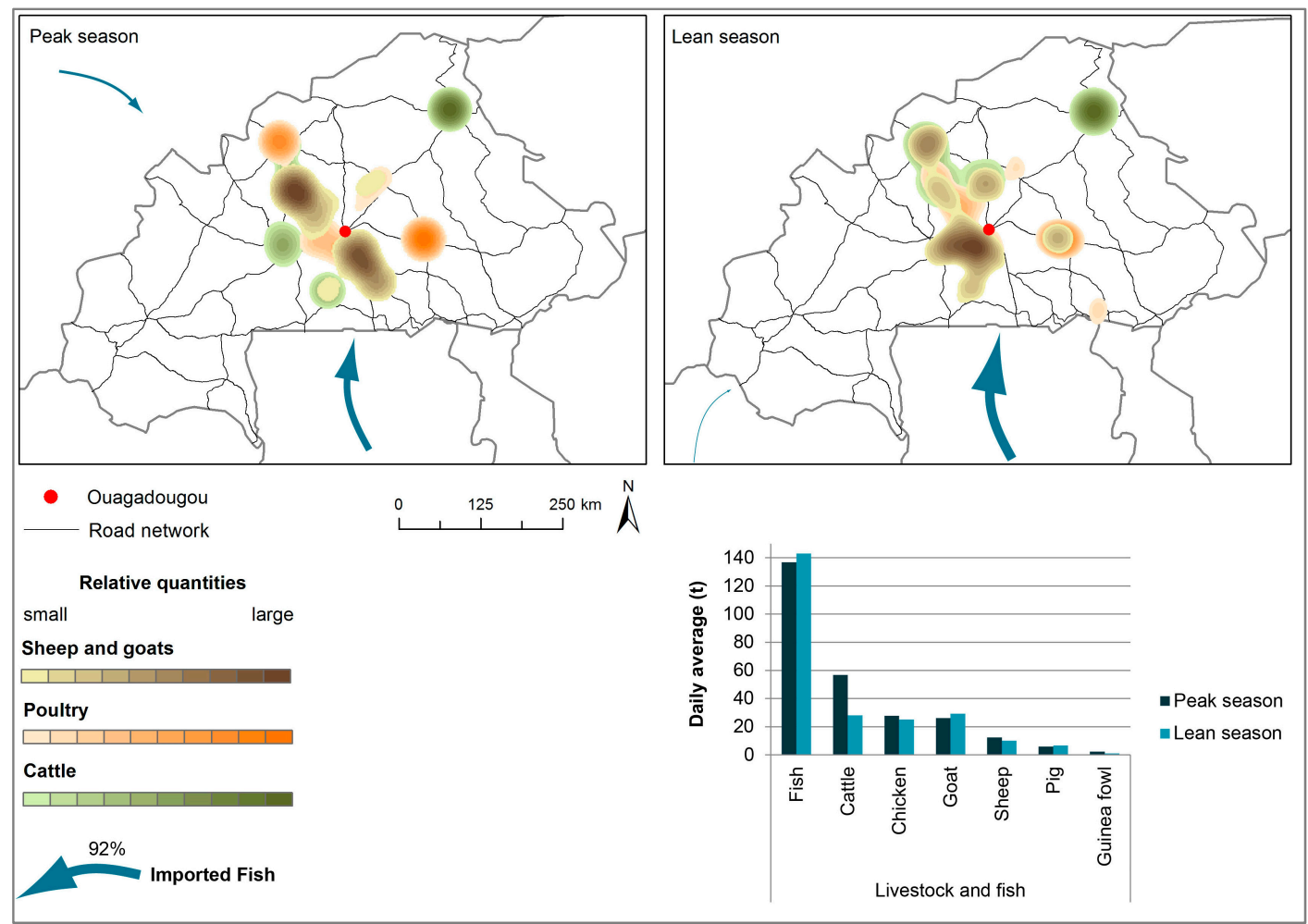

Figure 8. Seasonal livestock foodsheds for Ouagadougou and daily incoming quantities (in metric tonnes).

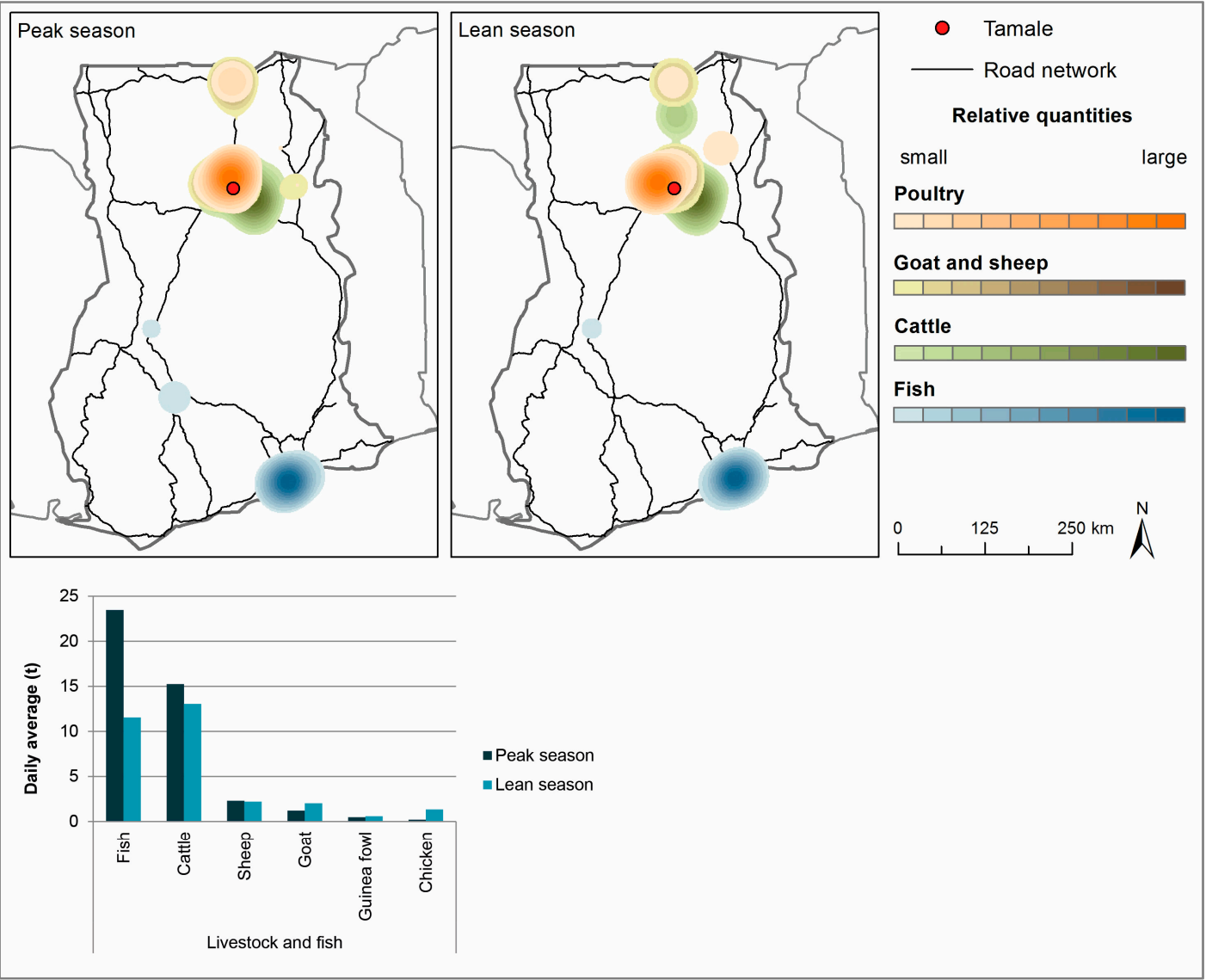

Figure 9. Seasonal livestock foodsheds for Tamale and daily incoming quantities (in metric tonnes). 
The livestock sector is a major pillar of Burkina Faso's economy contributing more than $18.6 \%$ (including forestry and fisheries) to the country's GDP and accounting for $25 \%$ of its export earnings [30]. Almost 300 cows entered Ouagadougou daily during the peak season. The main source was Dori in the northeast of the country, followed by Yako and Ouahigouya north of Ouagadougou. In the lean season, only half the cattle head entered the city as compared with the peak season. While Sahelian countries have good conditions producing domestic ruminants, the coastal countries are better suited for short-cycle livestock (poultry and pigs), especially in urban and peri-urban zones [17]. Accordingly, more than half the cattle head were exported, to Parakou (northern Benin), southern Ghana and Pouytenga, a city that serves as a trade hub between Burkina Faso, Niger and Benin. Ghana's cattle imports has risen five-fold in five years from 7192 head in 1993 to 35,946 in 1998, with Burkina Faso and to a lesser extent Niger as the two main sources [57]. Live cattle as well as small ruminants entering Tamale, however, came not from Burkina Faso, but from the surrounding areas. Northern Ghana is also suitable for livestock-keeping and even exported to the central and southern parts of the country; however, the main livestock trade occurred between Burkina Faso and the coastal cities of Ghana, passing through Tamale. Not only cattle but also small ruminants (sheep and goats) were exported from Burkina Faso to southern Ghana. They originated from dispersed sources in the central part of the country. In general, livestock-keeping is a potential source of income rather than for self-consumption and can be considered a risk-reducing strategy [57]. Therefore, it is difficult to assess the amount of meat that is being consumed in the two cities using livestock flow data. For example, for Ouagadougou, cattle are fattened in the city and it is only weeks later that they are exported to other countries. Consumption data may be a more reliable indicator of meat consumption.

Yet, generally, demand for livestock products including poultry is expanding in West Africa as a result of population growth, increased urbanisation, and rising incomes [58]. In many West African countries, the growing demand for poultry has been met by cheap poultry imports from Europe which was critically discussed given the "huge, untapped domestic poultry industry" in the region [17] (p. 32). This was made possible after the introduction of the Common External Tariff (CET) in West Africa that reduced the tariff rate to $20 \%$ [59]. It has had differing effects on poultry markets in the region, with some countries experiencing large import flows of frozen poultry such as Ghana and others like Burkina Faso receiving very little [58]. Schneider et al. (2010) [59] noted that despite similar import regulations and tariffs domestic production of chicken accounted for almost $100 \%$ of total consumption in Burkina Faso. This is reflected by the large inflow of live chicken into Ouagadougou. Our data showed that 16,000 chicken and 1000 guinea fowls entered the city daily, mostly by motorbike (Figure 10). Schneider et al. (2010) [59] assumed that the country's landlocked location, and the far distance to the next port prevented the influx of frozen poultry from Europe. Hence, trade barriers including high transport costs can, in some cases, also protect domestic production. On the other hand, Ghana imports more than half of its poultry supply [59] despite a flourishing poultry industry in the late 1980s [60]. This is reflected in the small number of chicken entering the city per day: 120-770 chicken and 300-245 guinea fowls in the peak and lean season, respectively.

Apart from onion (Allium cepa L.), urban vegetable supply in Ouagadougou was met by domestic production, albeit with large seasonal differences (Figure 11). In the peak season, vegetables entering the city stemmed from surrounding areas, while in the lean season, vegetables were produced in various locations throughout the country. It is likely that peri-urban areas of Ouagadougou and the rural hinterland take advantage of the proximity to the urban market in the peak season when weather conditions allow the cultivation of vegetables almost everywhere. In the lean season, however, vegetable production is limited to locations where irrigation water is available. Tomato (Lycopersicon esculentum L.) was produced in irrigation schemes such as in Yako, Titao, Kongoussi, while eggplant (Solanum melongena L.) as well as zucchini (Cucurbita pepo L.) came from irrigation schemes close-by, such as from Loumbila, Ziniare, and Zitenga. Most of the cabbage (Brassica oleracea var. capitate L.) was provided by areas close to Bobo Dioulasso. Part of the onion supply was produced in the country, and sourced from mainly Fada N'Gourma and Koupéla; 
but especially in the lean season the amount of imported onion from Niger exceeded domestic supply. Secondary import data at national scale indicate that apart from the largest exporter, Niger, onion is further imported from the Netherlands and Morocco to Burkina Faso. On the other hand, onion production in Burkina Faso is increasing and exports exceed the amount of imported onion [45]. Our data revealed that in both seasons, onions left the city again to Côte d'Ivoire and Ghana. Our data also showed that large volumes of onion moved from Niger and Burkina Faso to central and southern Ghana, passing through Ouagadougou and Tamale. Hence, no onions from Burkina Faso were recorded to end in Tamale and only a small part of the onion supply entering Tamale came from Niger. Informal interviews indicated that even though onions from Niger are appreciated by the customers, trade relationships are not yet well established between traders in Tamale and Niger. For example, traders on the Tamale market would be granted credit by their long-known supplier from Bawku in North Ghana while they had to pay for onions from Niger in cash (personal communication).

Apart from onion, tomato was traded across borders. According to secondary customs data, tomato produced in Burkina Faso in irrigated agriculture during the lean season was exported mainly to Ghana and Benin. Turnover in Ouagadougou before continuing to Ghana may explain the higher quantities of incoming tomato to Ouagadougou during this season. This is reflected in our data: Tamale sourced $84 \%$ of its tomato from Burkina Faso in the lean season (Figure 12). In the peak season, central Ghana, in particular Techiman and surrounding communities, provided fresh tomato from rain-fed cultivation. Market data collected on a monthly basis revealed that in January and February, Northern Ghana with its towns Navrongo and Bawku are additional suppliers in the lean season. However, the tomato industry in Northern Ghana has experienced a decline in the past years [61-63]. Tomato from Burkina Faso is considered of superior storage quality and therefore has higher retail prices [64] which was confirmed by informal interviews. Moreover, tomato paste imports surged in the 2000s, from 24,654 tonnes in 2003 to 109,513 tonnes in 2013, providing a low-cost substitute to fresh tomato. Other vegetables supplying Tamale such as hot pepper (Capsicum spp. L.) and okra (Abelmoschus esculentus L.) were produced in close vicinity to the city and the only crop that was only available seasonally was avocado (Persea americana L.) coming from the central part of Ghana as well as cabbage albeit with hardly any seasonal variaton.

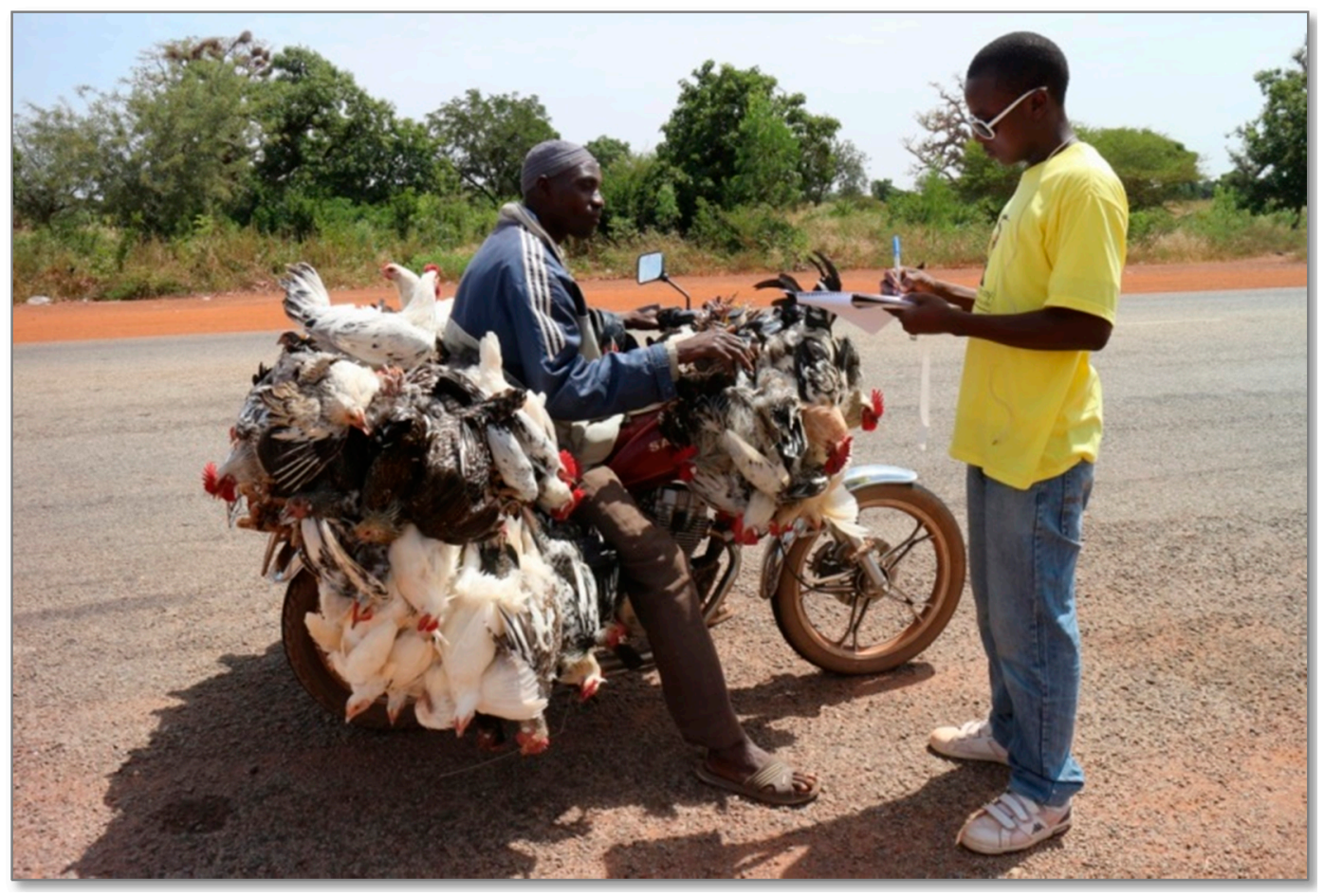

Figure 10. The number of chickens on a motorbike on an access road to Ouagadougou is recorded. 

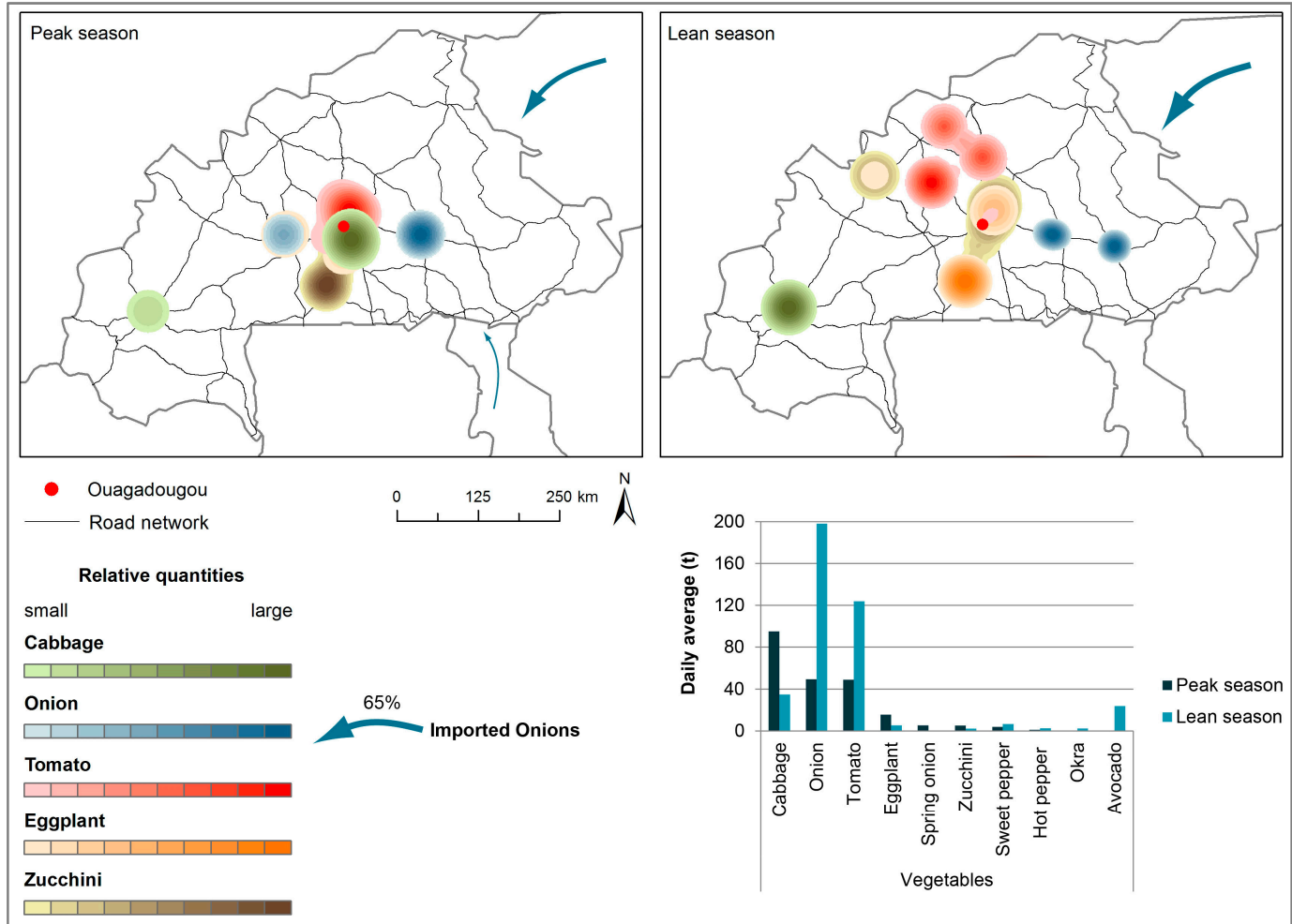

Figure 11. Seasonal vegetable foodsheds for Ouagadougou and daily incoming quantities (in metric tonnes).

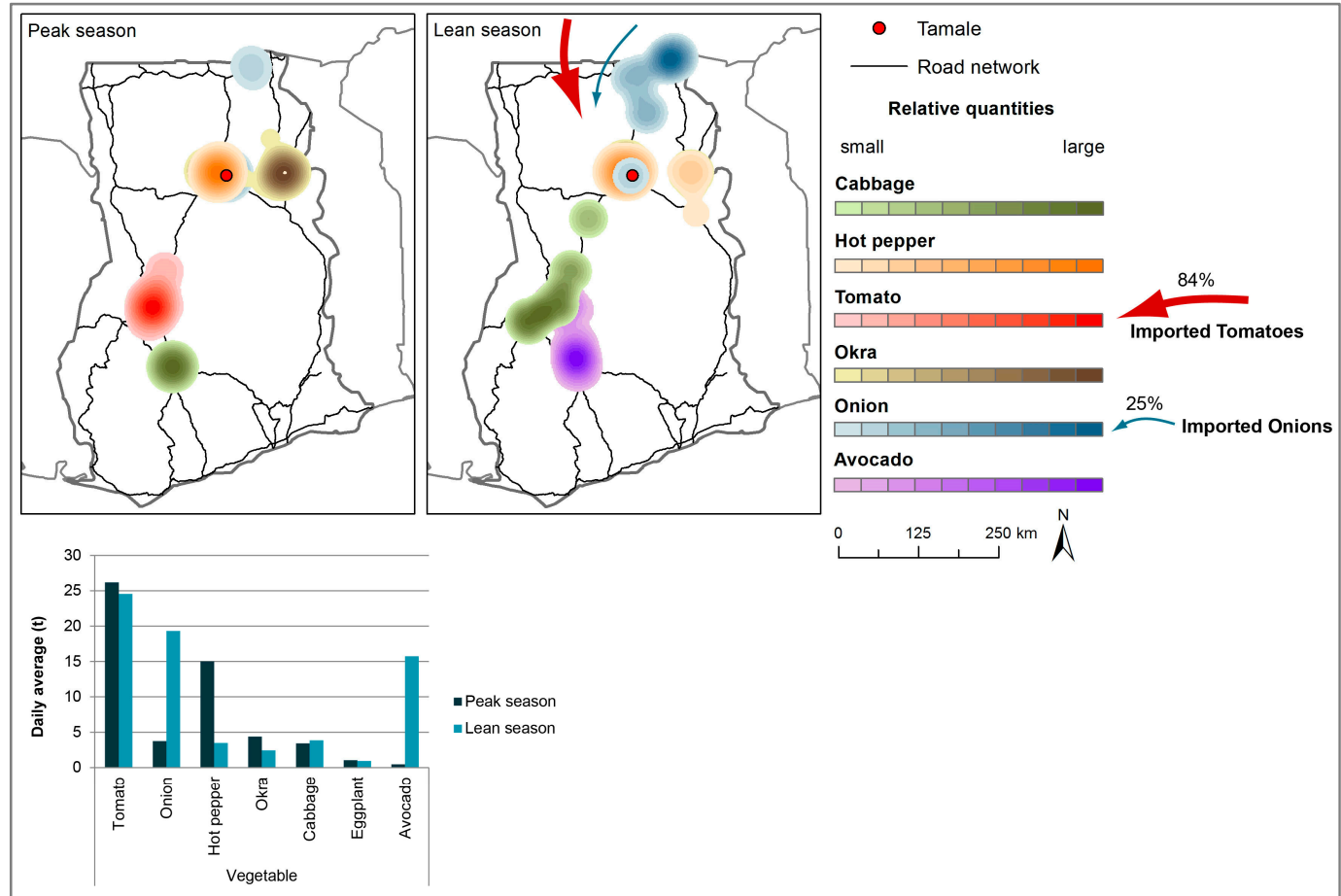

Figure 12. Seasonal vegetable foodsheds for Tamale and daily incoming quantities (in metric tonnes).

For Tamale, urban agricultural production could be captured by data collected at the inner urban market. These data revealed that urban agriculture supplied traditional leafy vegetables such as jute mallow (Corchorus spp. L.), roselle (Hibiscus sabdariffa L.) and amaranth (Amaranthus L.) as well as exotic 
leaf vegetables such as lettuce (Lactuca sativa var. capitate L.; Figure 13). Leaves take a substantial part of traditional diets and are an important source of Vitamin A. These were not the only crops cultivated in urban areas but the only ones that were supplied exclusively by urban farming. The perishable nature of the produce does not allow for long transport routes due to the lack of cool storage. Hence, crops produced in urban areas benefit from close proximity to the urban market. This has been documented for many African and Southeast Asian cities [65] in general and for Tamale and Ouagadougou in particular [33]. According to Drechsel and Keraita (2014) [66], 80\% of the cabbage supply was provided by urban agriculture in Tamale. This could not be confirmed by our data according to which only $3.6 \%$ and $6.2 \%$ of cabbage was sourced from within the urban area in the lean and peak season, respectively. It has to be noted that incoming quantities are rather conservative estimates, since only those volumes entering the main marketplace in Tamale were captured, while street sellers have not been considered who may market a considerable proportion of the leafy vegetables. Moreover, backyard gardening for subsistence as well as for commercial purposes is common [33].

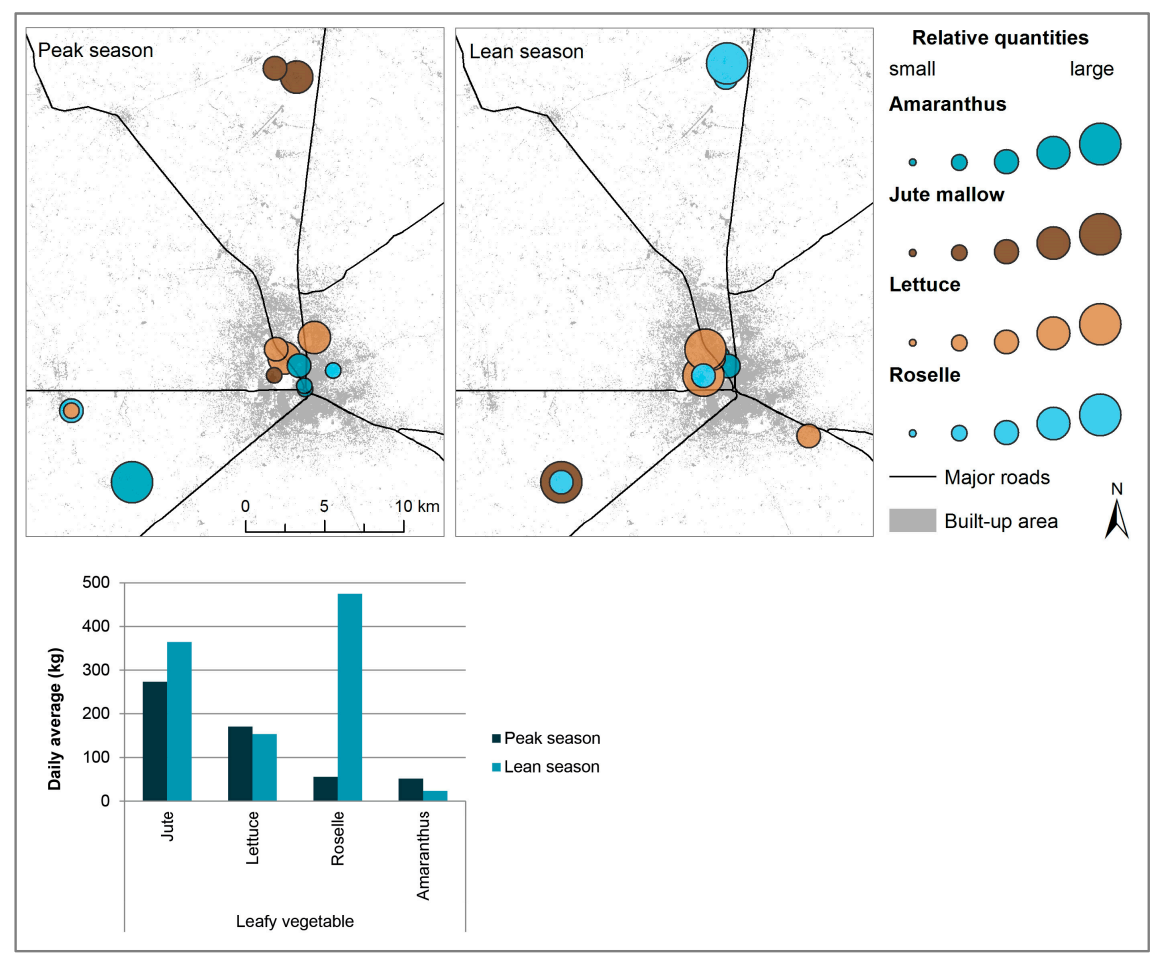

Figure 13. Seasonal leafy vegetable foodsheds for Tamale and daily incoming quantities (in kg).

\section{City Region Food Systems}

Due to lack of a common definition, we approached the city region considering the importance of surrounding areas for urban food supply. Specifically, we considered source locations as well as relative quantities provided by those locations to the urban population. This way, places of production as well as places of consumption are considered. Thus, the entire food system is taken into account, including all stages in the food chain from production to consumption. Moreover, we considered different groups of food items based on common classification schemes such as the FAO-based food groups and the most important food groups based on household food expenditure for urban populations in each country.

Results showed for both cities clear changes in the cumulative contribution of food along a distance gradient (Figures 14 and 15). There is a steep increase of contributions in short distances from the city centre and after a certain distance the growth declines. The data showed similar trends no matter which grouping was used (see Figures A1 and A2 for grouping based on household expenditure). This indicates that a variety of the most relevant crops come from the same source locations. 
In Ouagadougou, the distance from the urban centre at which the contribution of food items decreases was reached at $50 \mathrm{~km}$ and included $30 \%-32 \%$ of all crops and $20 \%$ of the major crops (Figure 14). For Tamale, the cut was already reached at $30 \mathrm{~km}$, likely due to the smaller size of the city and the corresponding smaller area it needs to supply $30 \%$ of the total food needs (Figure 15). Within that area $30 \%-40 \%$ of all food and $26 \%-28 \%$ of the major food was sourced. Another cut was reached at 100 and $105 \mathrm{~km}$, respectively, in both cities. In Ouagadougou, 50\%-55\% of all and $37 \%-45 \%$ of the major food items came from within a radius of $105 \mathrm{~km}$, while in Tamale the proportion ranged from $50 \%-58 \%$. In Tamale, $80 \%-90 \%$ of food items were sourced within a distance of $300 \mathrm{~km}$. In Ouagadougou, the proportion was smaller with $60 \%-80 \%$ of food originating from within the $300 \mathrm{~km}$ radius.

Thus, two distance boundaries are suggested for the extent of city regions, i.e., the $30 \%$ city region (CR) and the $50 \%$ city region, named according to their lean-season contribution of all crops.

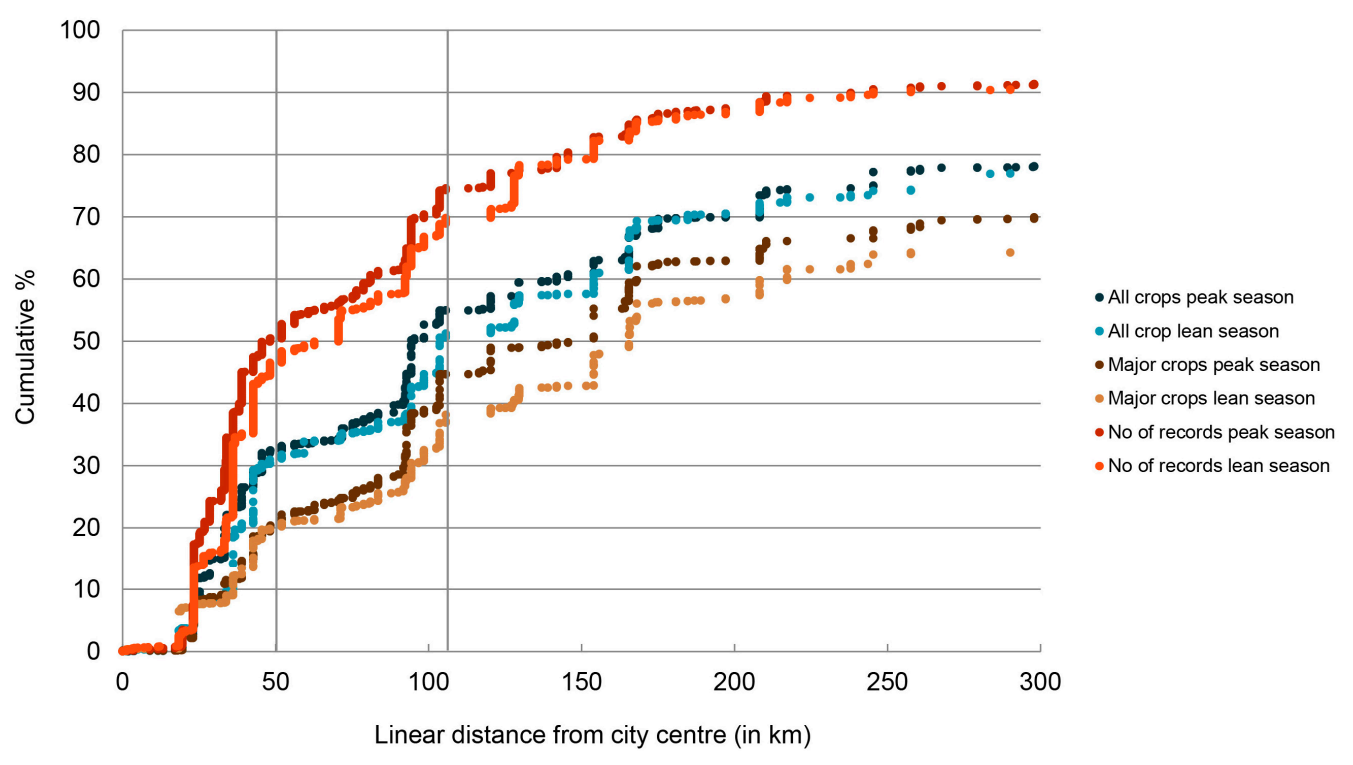

Figure 14. Cumulative food contribution along a distance gradient in Ouagadougou in 2014. The grey vertical lines indicate the $30 \%$ and the $50 \%$ city region on the basis of the lean season supply of all crops.

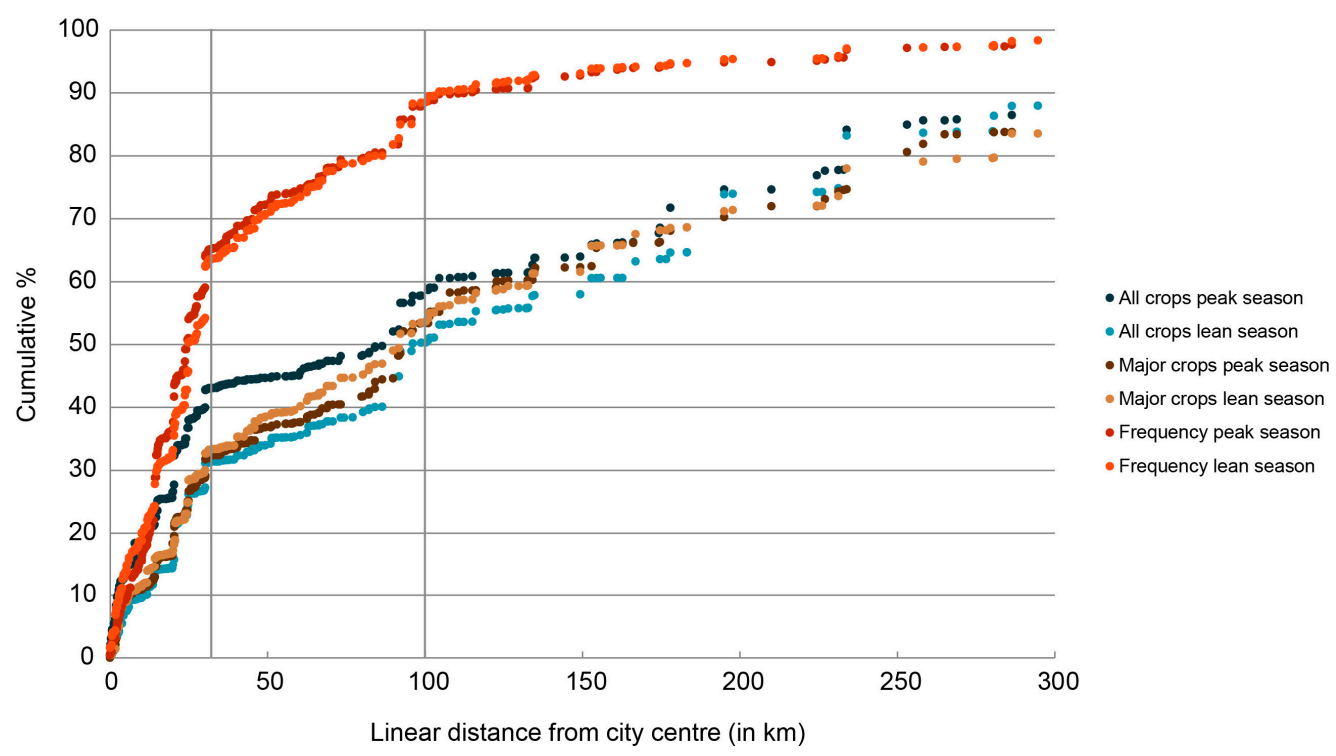

Figure 15. Cumulative food contribution along a distance gradient in Tamale in 2013-2015. The grey vertical lines indicate the $30 \%$ and the $50 \%$ city region on the basis of the lean season supply of all crops. 
While in Ouagadougou almost one-third of the food originated from the $50 \mathrm{~km}$ radius (30\% city region), the number of records reached up to $50 \%$ (in the peak season). In Tamale, in the peak season, even up to $60 \%$ of all records came from within the $30 \%$ city region, as compared with $40 \%$ of the food quantities. Within a distance of $100 \mathrm{~km}$, the ratio rose to $88 \%$ of the records.

This means that within the $30 \%$ city region in both cities, about half of the interactions including the exchange of food, people and money take place. In turn, this means that on average, smaller quantities per vehicle recorded enter the city from within that area while larger quantities are transported from further away. This is reflected by the means of transport used for carrying food. In Ouagadougou, within the $30 \%$ city region, small vehicles (such as bicycles, motorbikes and tricycles, not considering mini buses) constituted $89 \%$ of the records, carrying $20 \%$ of the weight-based quantity to different markets in the city (Figure 16). In Tamale, small vehicles accounted for $82 \%$ of the vehicles entering the city, carrying $62 \%$ of the overall food into the city. This is due to the large number of motorised tricycles in Tamale that carried almost half of the food from the $30 \%$ city region into the city, which is more than that carried by trucks and articulators. The share of small vehicles as well as the quantities they transported decreased by the area that is considered. While small distances can be covered by small vehicles, only larger-scale transportation (large-scale production or assembling the produce at a wholesale market) can cover longer distances. However, it means that small-scale producers in the vicinity of the city have the opportunity to market their produce on urban markets. Thus, distance is a determining factor of market access which according to OECD (2013, p. 116) [49] is "an economic concept as much as a physical one", indicating "how easily goods are transported, services are delivered and information, capital and labour move between two locations".

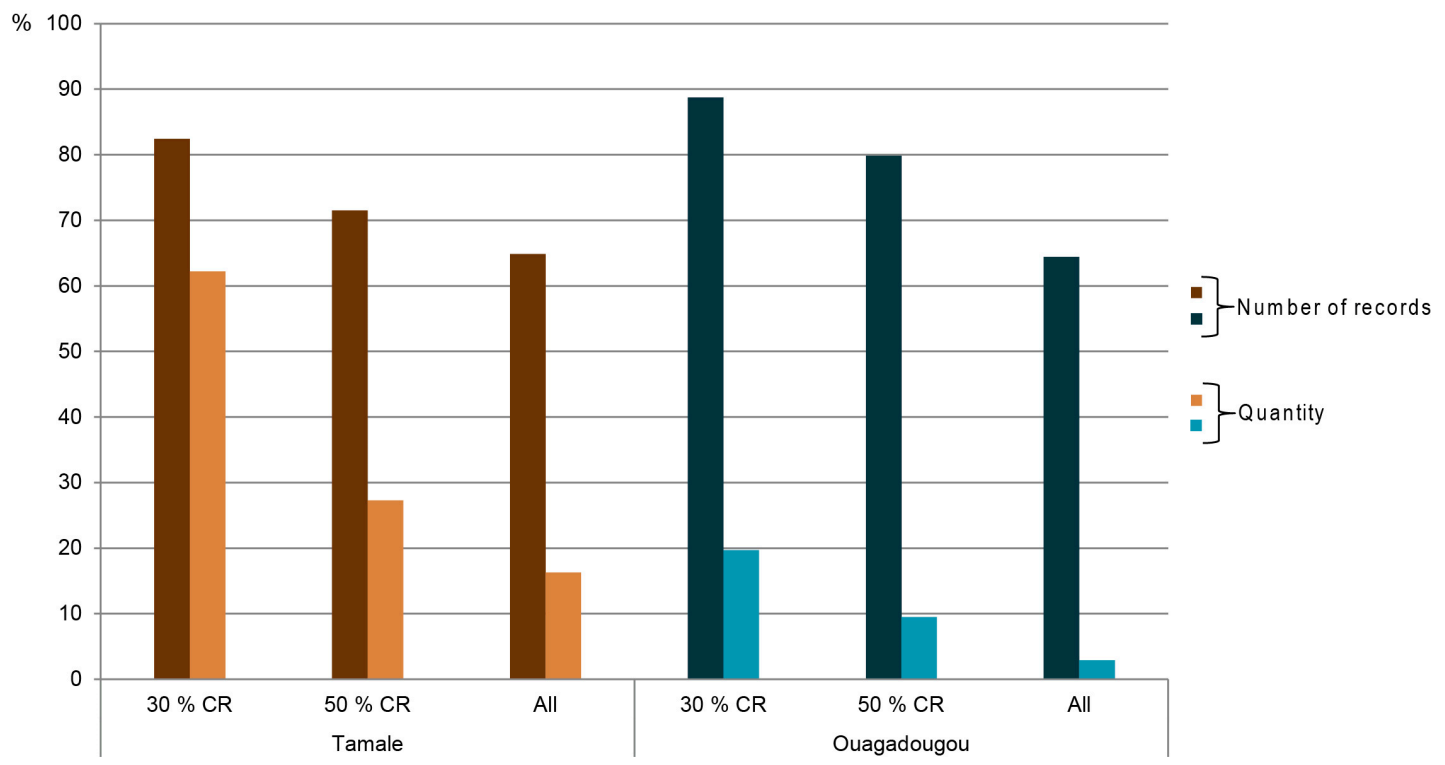

Figure 16. Contribution of small vehicles to overall food supply from the $30 \%$, and the $50 \%$ city region and all sources in Tamale and Ouagadougou (in terms of weight-based quantity as well as the number of records; mean of peak and lean values).

Obviously, the boundaries of a city region do not follow concentric radii but include the major supply areas, and are more extensive along roads. Therefore, a city region can also extend towards one direction and form a rather oblong shape. We drew the boundary along the major source locations as indicated by their contribution to urban food supply. The number of records from one source location further reflects the importance of a location, even of an area for urban food supply. As the maps (Figures 17 and 18) show, the extents of the city region-whether containing 10\%, 30\% or 50\% of the supplied food-are not "flat" areas, but the quantitative contribution of food as well as the number of records vary within the zone. In Tamale, within the $30 \%$ city region, peri-urban villages 
with marketplaces contributed the most, while the $50 \%$ city region clearly goes beyond what can be considered peri-urban in the case of Tamale [67]. The villages and small towns located northeast of Tamale in the $50 \%$ city region are part of the north-eastern periodic market system and have traditionally provided local produce, in particular cereals, to Tamale [68].
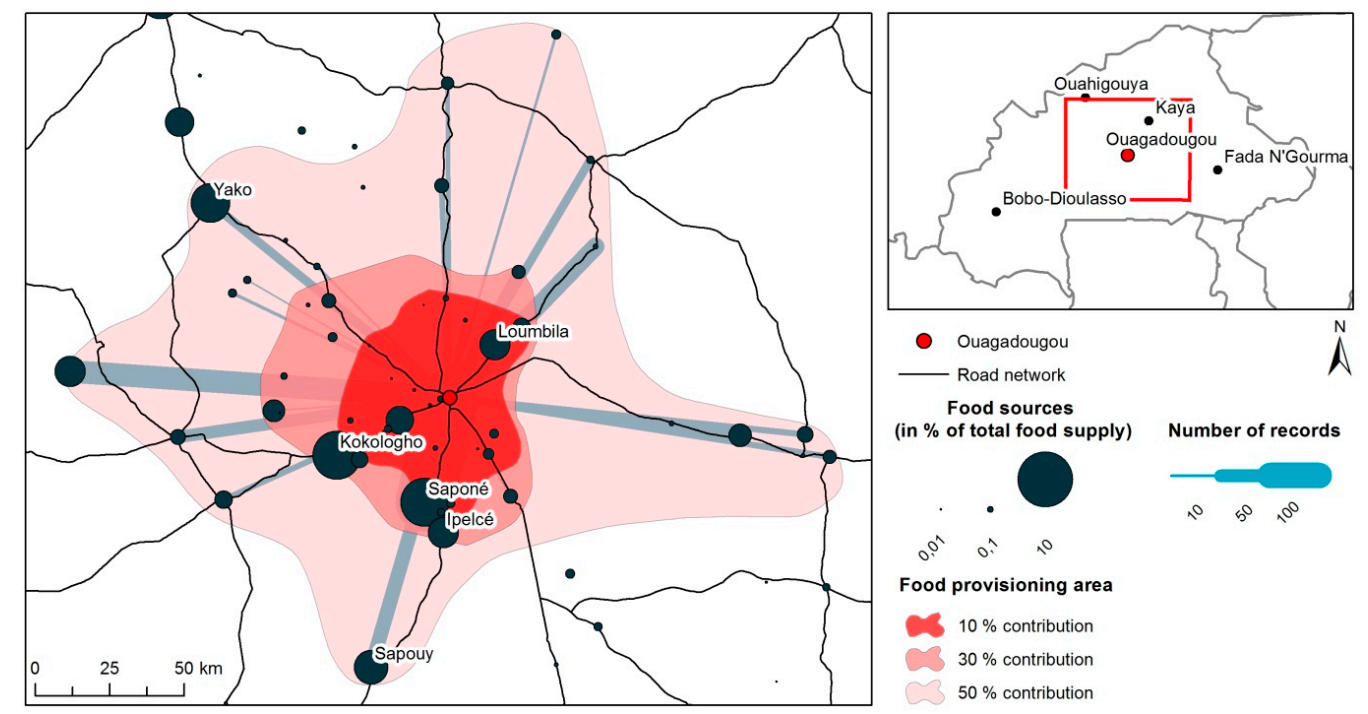

Figure 17. Extents of the city region of Ouagadougou in the lean season 2014 (based on quantitative contributions and number of records).
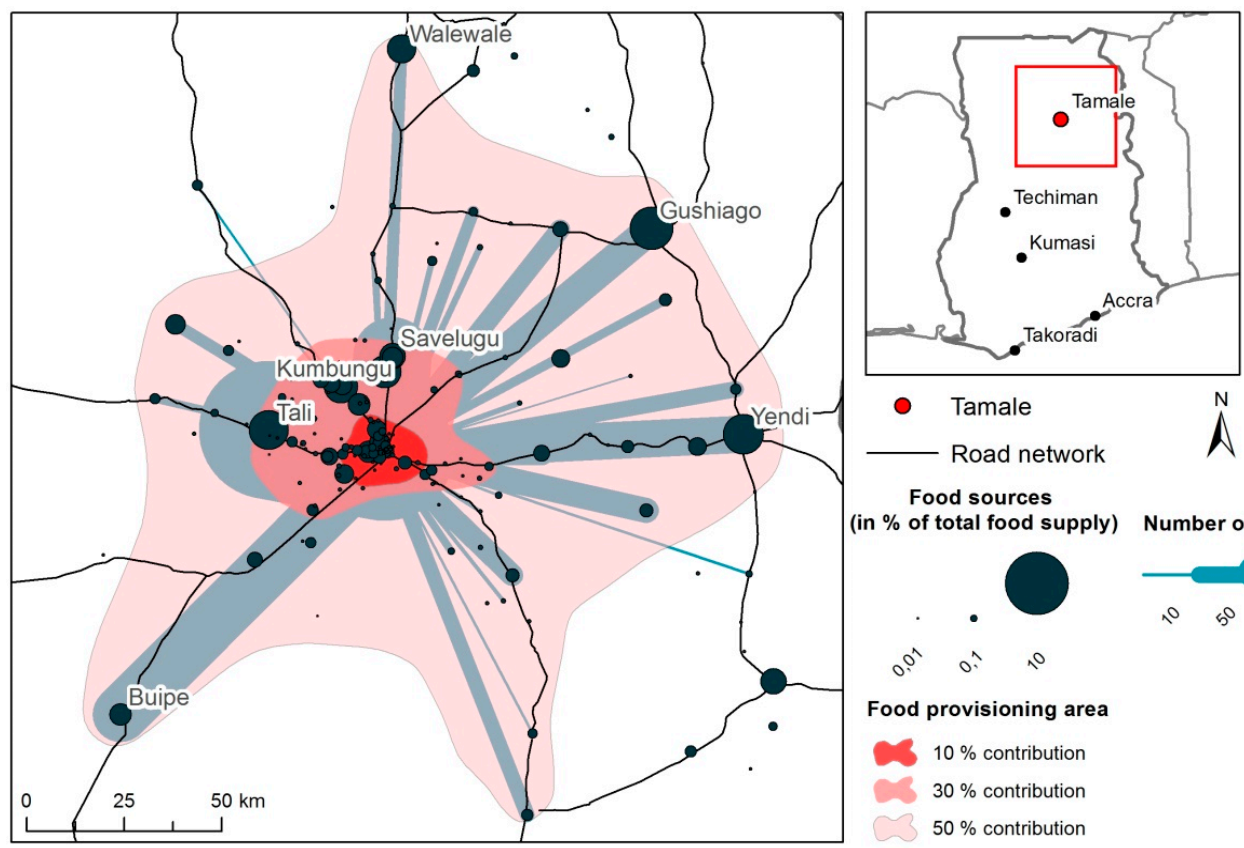

Figure 18. Extents of the city region of Tamale in the lean seasons 2014/2015 (based on quantitative contributions and number of records).

In terms of type of food, the $10 \%, 30 \%$ and $50 \%$ city regions show different crop-specific contributions (Figure 19). Supply of fish did not play a role in either city region, and rice in Ouagadougou was mainly coming from outside the city region. However, the otherwise large variety highlights the actual importance of these areas for urban food supply. For Ouagadougou, the city region provided the majority of vegetables, while in Tamale especially the livestock and 
cereal sectors dominated the city regions. Leafy vegetables stemmed from the $10 \%$ and $30 \%$ city region, i.e., from urban and peri-urban agriculture. In Ouagadougou, data on leafy vegetables are not complete (including only jute mallow and roselle) since urban agricultural production was not captured. However, other studies confirmed the production of leafy vegetables in the city [33].

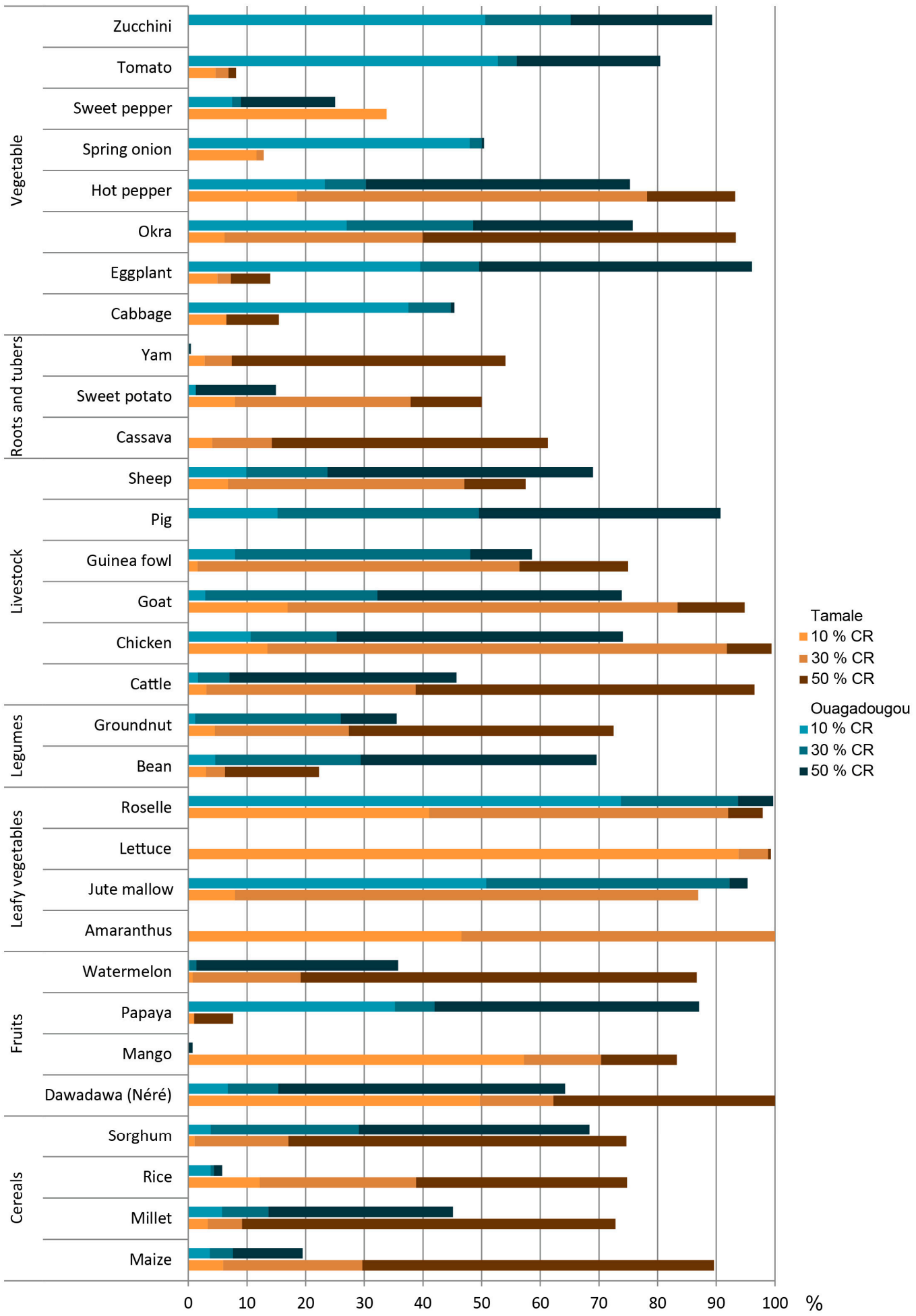

Figure 19. Contribution of individual crops originating from the $10 \%, 30 \%$, and $50 \%$ city region extents to urban food supply (mean values of peak- and lean-season supply). 
The approach of delineating a boundary of the city region presented here is one possible approach and even within this one approach, more than one boundary is possible depending on the scale of a city region. A common understanding, however, will be useful to making meaningful comparisons, and it is particularly important to use one boundary per city to monitor changes over time.

\section{Sensitivity Assessment}

In general, the better the transported quantities are distributed over a large number of vehicles, the less sensitive the data are to human error like missing or miscounting a certain number of vehicles. The sensitivity analysis showed, for example, that the captured quantities of onion and fresh fish, which are usually transported in a few large articulated lorries, are most sensitive to errors and missed records. However, the probability of missing such trucks is much lower than missing some of the many bikes in Ouagadougou carrying chicken. The commodities most sensitive to the chosen methodology are onion and fish (Tamale, peak and lean season) and yam and groundnut (Ouagadougou, lean season), where one or two missed/miscounted vehicles can result in a $10 \%$ change of the total transported volume. Removing, irrespective of the commodities, five of the most common vehicles per survey and crop, the outcome of the reported total food flow would change for Tamale by about $16 \%$ and for Ouagadougou by about $13 \%$. Although such an omission is unlikely, the numbers indicate the possible error margin. As a function of food volume and distinct geographical food sources, the city region boundary would only change if the survey missed any important production area which did not supply both cities in the observation weeks of lean and peak season. This is theoretically possible especially at the start and end of a growing season as the onset of rains and eventual harvest dates vary to some extent and certain areas might be able to supply particular commodities earlier or later than the mainstream. These sources would not have been captured. Secondly, there can be geographical changes in foodsheds due to natural hazards, like flooding, when traders look for alternative sources to maintain their supply as much as possible. Such variations were not covered in this paper, but are captured in Drechsel et al. (2016) [69].

\section{Implications for Planning}

\subsection{Impacts on the City Region}

Our results show that up to $50 \%$ of the urban food needs, covering the main food groups, is met by the proposed city region with an average radius of about $100 \mathrm{~km}$. Thus, this region is significantly contributing to feeding the urban population. Planning in accordance with the aims of a CRFS approach would involve preserving or even increasing the share of food sourced from the city region. Relative to the limited area size, cultivation in and near the city contributes considerably to urban food supply, particularly in Tamale where $30 \%$ of all crops originates from peri-urban and nearby rural areas. Also, urban production is important for the supply of certain products such as leafy vegetables. Maintaining urban production and urban-peri-urban linkages in the future can be achieved by incorporating food production into urban planning, e.g., by designating and allocating land permanently to agriculture.

It is not only urban populations that benefit from the production in city regions, but also urban as well as rural enterprises along the entire value chain such as wholesalers, transporters, processors, and input suppliers. Urban demand for high-value products like fruits, vegetables, and dairy can further contribute to rural poverty alleviation and agricultural development [2]. Our results indicate that a substantial share of the city region production is covered by smallholders. In Tamale, small vehicles carry more than $60 \%$ of the fresh food weight from the $30 \%$ city region into the city. In Ouagadougou, where urban and part of peri-urban sources were not captured, the share is smaller. There, $20 \%$ of all crops were transported by small vehicles. While rural farmers without access to urban markets usually market their produce in the next village or small town market that may act as intermediate stopping off points to the urban market [9], farmers close to urban markets may have better options for direct marketing with fewer intermediaries. Thus, physical proximity to 
the urban market provides market opportunities to small-scale farmers in the city region that their remote rural counterparts do not have. Therefore, strengthening CRFS potentially supports local small-scale producers. As a result of growing urban demand for food, a city region is likely to expand geographically and involve more remote farmers in the future. Thus, adopting a CRFS approach allows linkage to general economic urban and regional development which could be part of communication strategies with local authorities.

Proximity of places of both crop production and food consumption also offers options for resource recovery and reuse. Poor soils and high cost of inorganic fertiliser are major obstacles for farmers in Tamale and Ouagadougou [33], as generally in the Savannah Region. At the same time, urban food demand is increasing and so is the organic waste generated in the cities. Poor sanitation systems in cities of developing countries result in widespread environmental pollution and health risks. In particular, agricultural land close to the city can benefit from nutrients that accumulate in the form of wastewater and faecal sludge in the urban centre. Recovering human waste for instance via co-composting for reuse in crop production can make urban waste management viable and provide valuable nutrients to farmers. While transferring accumulated nutrients from food imports back to distant sources is challenging, their reuse in the city region, particularly in nearby urban and peri-urban agriculture, is more feasible [70].

A CRFS approach, strengthening urban, peri-urban, and rural linkages, can hence have positive place-based impacts regarding the sustainable management of waste, urban food supply and economic development.

\subsection{Balanced Foodsheds}

Tackling urban food supply, however, requires a holistic perspective beyond the city region. Even though its contribution is substantial, cities are integrated into a national, continental and global market and can benefit from trade, linking surplus with deficit areas.

Foodsheds revealed that certain crops were solely provided by outside the city region and that some products were only available seasonally. Examples of so-called one-dimensional foodsheds include the supply of tomato from Burkina Faso to Tamale during the lean season or the reliance of Ouagadougou on imported rice. Both are important ingredients of local diets and cannot be easily substituted by domestic production that has declined as a result of imports. Tariff regulations, road damages, or the closure of borders will seriously affect the supply of these crops, in particular on perishable produce such as tomato. The supply of imported rice may be affected by volatile world market prices or transport issues. For example, the political crisis in Côte d'Ivoire, referred to as the historically main transit route by Bourdet (2004) [32], made Burkina Faso to change transport routes which resulted in higher freight and other transaction costs. On the other hand, imported goods, rice in particular, are transported by both road and railway. Different means of transport may also help to reduce vulnerabilities in case one fails.

Nonetheless, relying solely on local production may also be risky. The 2007 drought and subsequent flooding seriously hit the three northern regions in Ghana. As a consequence, $50 \%$ of staple crops were destroyed and the population was affected by food shortages and rising food prices [71]. Reliance upon one source can make the city more vulnerable to disturbances that can be internal or external, cyclical or structural, sudden or gradual [72]. Diversification of food sources, thus creating multiple value chains, can hence be an important means to encounter place-based disturbances such as climate-related risks, border closures, or infrastructural damages.

Therefore, in addition to strong city region food systems, balanced multi-dimensional foodsheds are an important determinant for secured urban food supply. Just as Forster and Escudero (2014, p. 6) [13] promote a more integrated and multi-level approach instead of a polarised dialogue between the "ideology of the local" and the "ideology of the global". According to them, the focus of CRFS is more on local decision-making as to "when to rely on different sources of food as conditions change" and how food system objectives cohere with other regional priorities. Drechsel et al. (submitted) [70] point to the challenges of integrating scientific results and new concepts into urban planning. They 
relate to the lack of public authority in charge of urban food supply as well as to differing local priorities and policy objectives. These local conditions need to be taken into consideration and strategies communicated accordingly when planning towards enhanced city region food systems or balanced foodsheds.

\section{Conclusions}

Locality in urban food provisioning has gained increasing attention in the past years. Advocates of "local food" systems stress aspects of community development, reduced food miles and nutrition that go along with local production whereas others believe in diversified source locations of food supporting more resilient urban food systems. While there is much debate on the relevance of locality of food sources for urban food supply, there is hardly any empirical evidence regarding the actual geographical areas that provide cities with food.

The surveys conducted in Tamale and Ouagadougou generated a unique set of quantitative data of food flows linking the cities with nearby and distant source locations. Crop- and season-specific foodsheds revealed the level of spatial and temporal diversity, ranging from one-dimensional to multi-dimensional foodsheds. The data were also used to suggest extents of city regions, including those areas around the cities that contribute substantially to urban food supply. The results indicated that within the defined city region a relatively large proportion of smallholders contributed to urban food supply, taking advantage of the proximity to urban markets. Localised food systems potentially support smallholders, and also offer other place-base benefits, e.g., options for the reuse of organic waste generated in the city.

Increasing globalisation, contributing to a year-round availability of food and the supply of imported and processed food, will likely change and expand current foodsheds, and the relation of a city to its city region, and its function within it, may change as it develops. Complementing local food supply sources with other national and continental sources may enhance systemic resilience, given that place-based risk factors, e.g., climate risks such as floods, could affect the entire production. Sole reliance on international sources, however, is also risk-prone. For example, cross-border trade among the ECOWAS countries seems still far from ensuring a smooth and reliable supply in the short term, although economic integration may be desirable and support food security in the region in the long run.

There is no universal level of self-sufficiency, e.g., at the city region scale, or a right level of reliance upon distant food sources, but this is open to debate, is locally very specific and needs to be in line with other sometimes conflicting priorities at the city level. Understanding urban food needs and current foodsheds can help to develop strategies for a better management of urban food supply towards increasing local production, or diversifying food sources.

Acknowledgments: This study was carried out as part of the project UrbanFoodPlus, co-funded by the German Federal Ministry of Education and Research (BMBF) and the Federal Ministry of Economic Collaboration and Development (BMZ), under the initiative GlobE-Research for the Global Food Supply, grant number 031A242-A and 031A242-D with support from the CGIAR research program on Water, Land and Ecosystems. We thank the Northern Regional Command of the Ghana Police Service (Tamale, Ghana), the Customs Division of the Ghana Revenue Authority (Tamale, Ghana), and the Direction Général du Trésor et de la Comptabilité Publique in Ouagadougou for the permission to work at the check points and for their kind collaboration. Furthermore, we thank Désiré Jean-Pascal Lompo and Zacharia Gnankambary from INERA, as well as Boubacar Barry and Bazoin Igor Bado from WASCAL for their valuable logistical support. We also thank the institutions that kindly provided secondary data and Koffi Alexis for data acquisition in Côte d'Ivoire. We are grateful to the numerous helpful partners and enumerators in the field.

Author Contributions: Hanna Karg conceived and designed the research, collected and analysed the data, and wrote the manuscript. Pay Drechsel contributed significantly to the research design, data analysis and manuscript writing. Edmund K. Akoto-Danso co-designed the research, collected the data, and contributed to writing the manuscript. Rüdiger Glaser gave conceptual advice and contributed to writing of the manuscript. George Nyarko provided technical and logistical support in the field, and contributed to writing the manuscript. Andreas Buerkert conceived parts of the research and contributed to writing the manuscript.

Conflicts of Interest: The authors declare no conflict of interest. 


\section{Appendix A}

Table A1. Most common food items based on FAO food groups.

\begin{tabular}{|c|c|c|c|c|}
\hline & \multicolumn{2}{|c|}{ Ouagadougou } & \multicolumn{2}{|c|}{ Tamale } \\
\hline & Peak & Lean & Peak & Lean \\
\hline \multirow{3}{*}{ Cereals } & Rice & Rice & Maize & Maize \\
\hline & Maize & Maize & Rice & Rice \\
\hline & & Millet & Millet & Millet \\
\hline Fish & Fish & Fish & Fish & Fish \\
\hline \multirow{4}{*}{ Livestock } & Chicken & Chicken & Goat & Goat \\
\hline & Goat & Goat & Cattle & Cattle \\
\hline & Cattle & Cattle & Sheep & Sheep \\
\hline & Sheep & Sheep & & \\
\hline \multirow{2}{*}{ Fruits } & Banana & Mango & Watermelon & Mango \\
\hline & Watermelon & Dawadawa (Néré) & Orange Banana & Banana \\
\hline \multirow{3}{*}{ Vegetables } & Cabbage & Cabbage & Onion & Onion \\
\hline & Tomato & Tomato & Pepper (hot) & Avocado \\
\hline & Onion & Onion & Tomato & Tomato \\
\hline Leaf vegetables & & & $\begin{array}{l}\text { Roselle } \\
\text { Jute }\end{array}$ & $\begin{array}{l}\text { Lettuce } \\
\text { Jute }\end{array}$ \\
\hline \multirow[t]{2}{*}{ Legumes } & Groundnut Bean & Groundnut Bean & Groundnut Bean & Groundnut Bean \\
\hline & Sweet potato & Potato & Cassava & Cassava \\
\hline \multirow{2}{*}{ Roots and tubers } & Yam & Yam & Plantain & Plantain \\
\hline & & & Yam & Yam \\
\hline
\end{tabular}

Table A2. Food groups in terms of household expenditure.

\begin{tabular}{ccc}
\hline & Household Expenditure on Little to Non-Processed Food (in \%) * \\
\cline { 2 - 3 } & Burkina Faso & Ghana \\
\hline Other cereals, flour and other products & $\mathbf{2 8 . 1 1}$ & 6.25 \\
Rice & $\mathbf{2 0 . 4 9}$ & $\mathbf{1 1 . 2 1}$ \\
Vegetables including legumes & $\mathbf{1 8 . 0 7}$ & $\mathbf{1 5 . 0 2}$ \\
Fish & $\mathbf{1 1 . 0 0}$ & $\mathbf{2 3 . 6 4}$ \\
Beef and veal & $\mathbf{5 . 4 4}$ & 1.89 \\
Frozen, preserved or processed vegetables & 5.38 & 0.53 \\
Lamb, mutton and goat & 4.33 & 8.29 \\
Fresh fruit & 1.87 & $\mathbf{9 . 4 8}$ \\
Roots and tubers & 1.73 & $\mathbf{1 4 . 4 3}$ \\
Frozen, preserved or processed fruit & 0.83 & 3.08 \\
Poultry & 0.75 & 3.04 \\
Other meats and meat preparations & 0.68 & 0.52 \\
Eggs and egg-based products & 0.56 & 2.02 \\
Fresh milk & 0.40 & 0.11 \\
Pork & 0.36 & 0.48 \\
\hline
\end{tabular}

* Top five food groups in bold. 


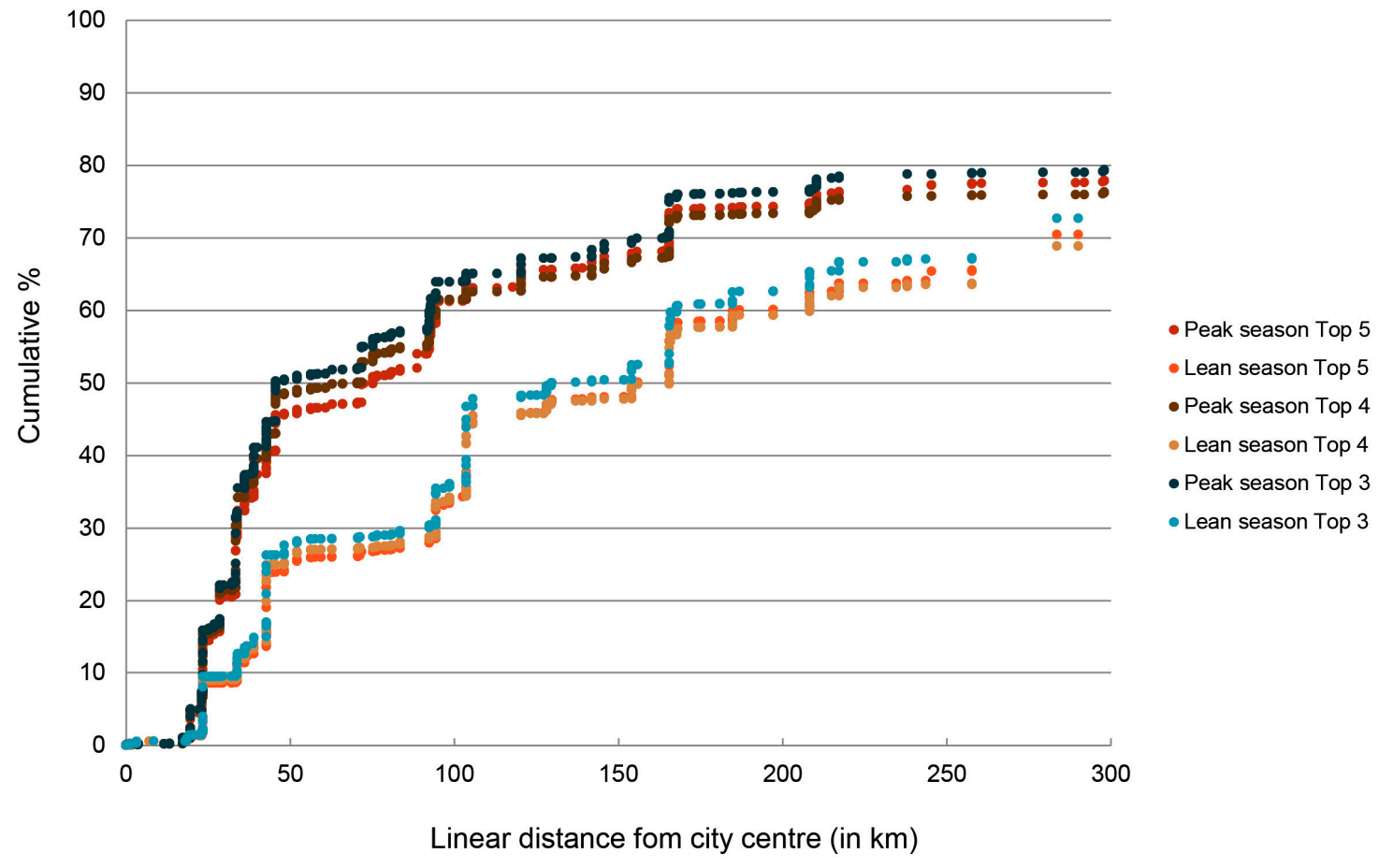

Figure A1. Cumulative food contribution based on the highest ranking food groups in terms of household expenditure along a distance gradient in Ouagadougou in 2014.

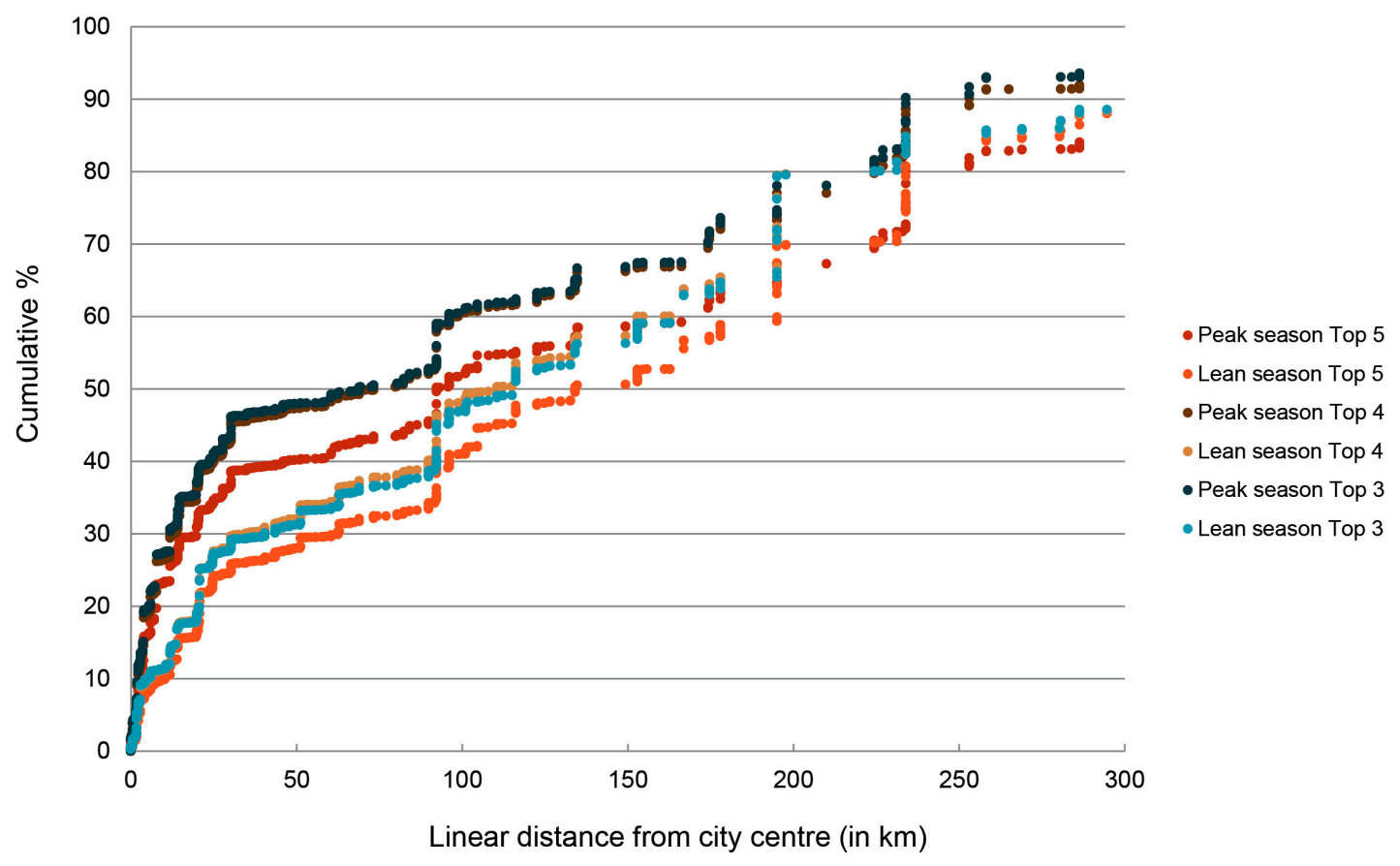

Figure A2. Cumulative food contribution based on the highest-ranking food groups in terms of household expenditure along a distance gradient in Tamale in 2013-2015. 


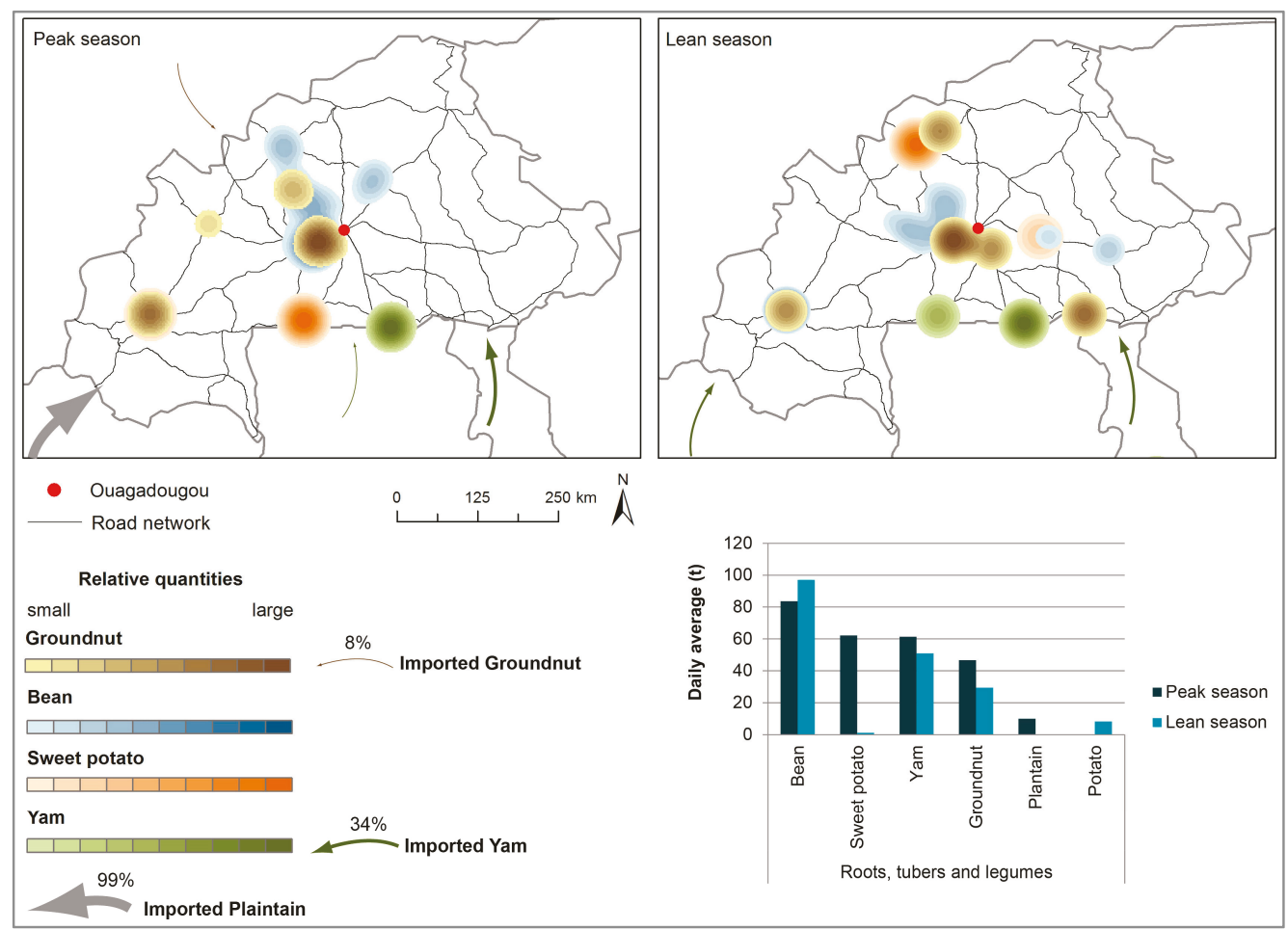

Figure A3. Seasonal foodsheds for tubers and legumes for Ouagadougou and daily incoming quantities (in metric tonnes).

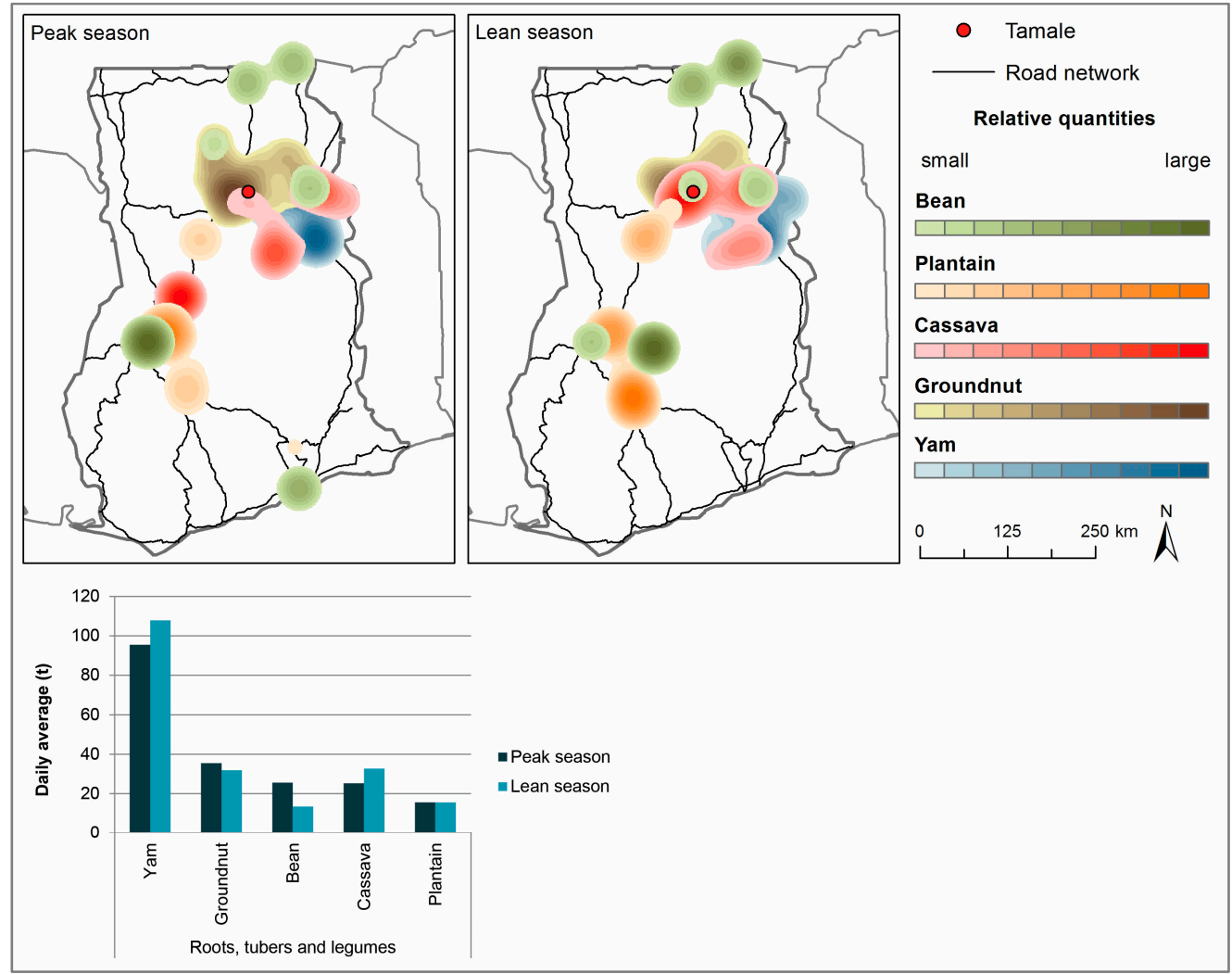

Figure A4. Seasonal foodsheds for tubers and legumes for Tamale and daily incoming quantities (in metric tonnes). 


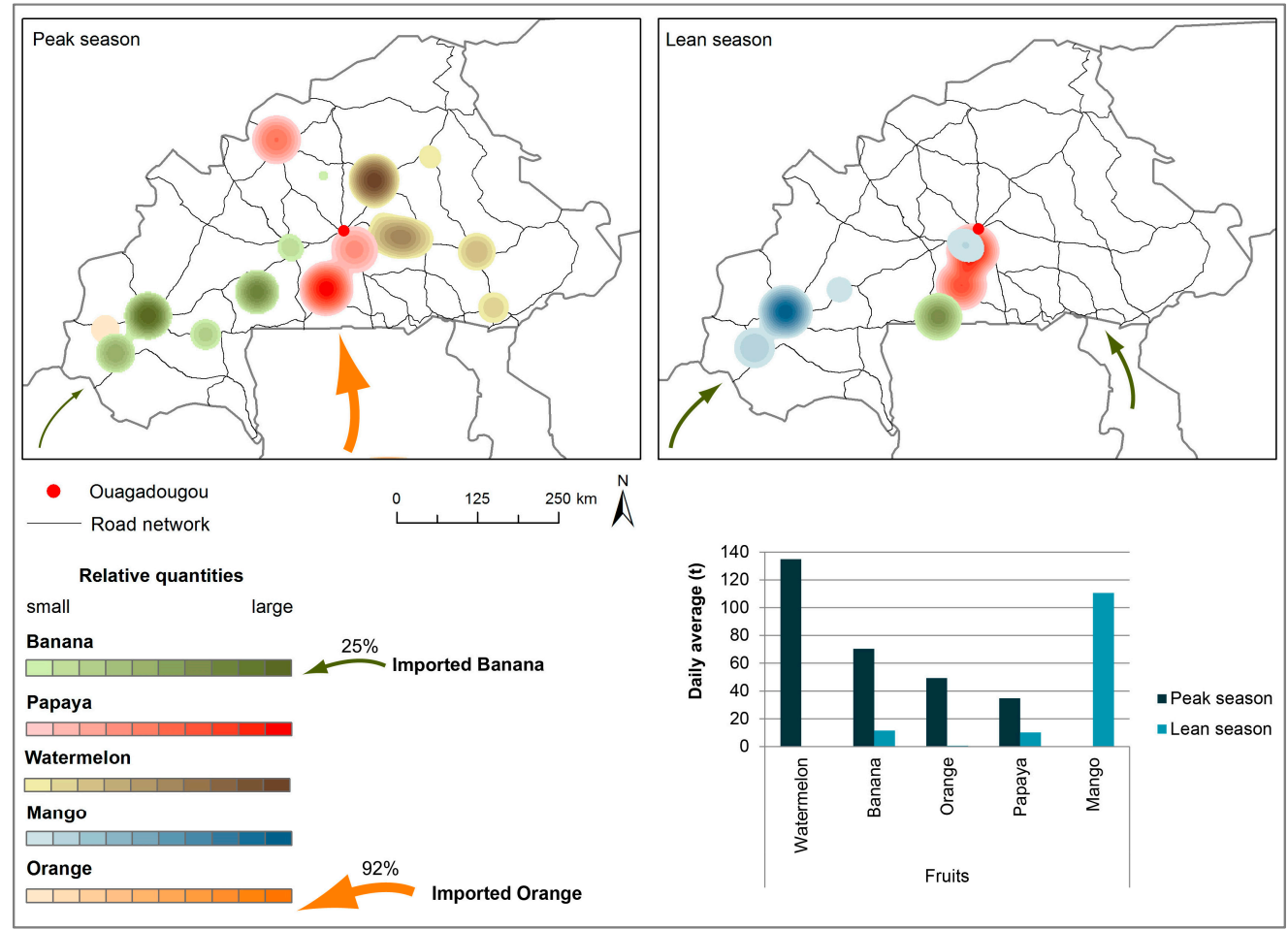

Figure A5. Seasonal fruit foodsheds for Ouagadougou and daily incoming quantities (in metric tonnes).
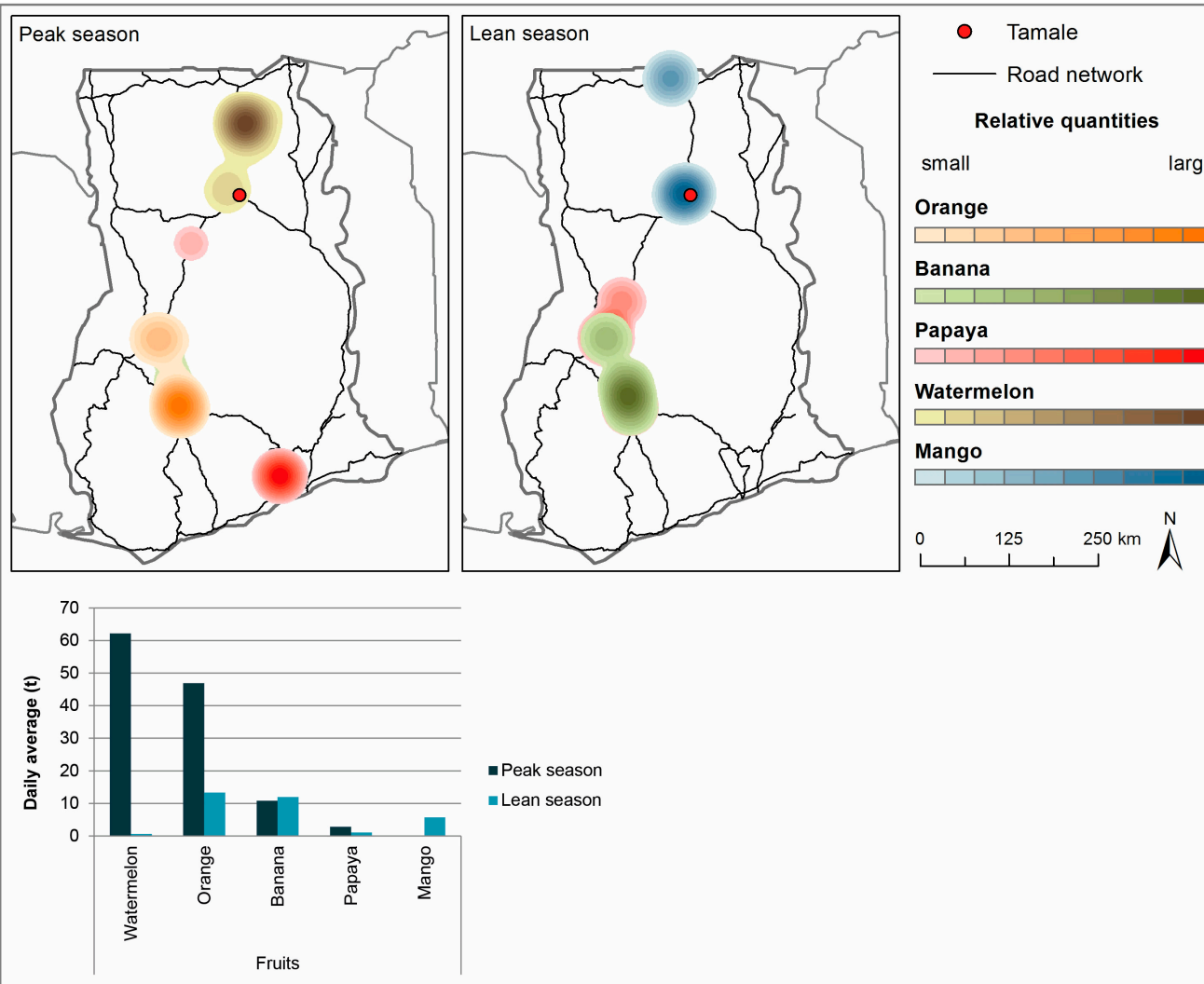

Figure A6. Seasonal fruit foodsheds for Tamale and daily incoming quantities (in metric tonnes). 


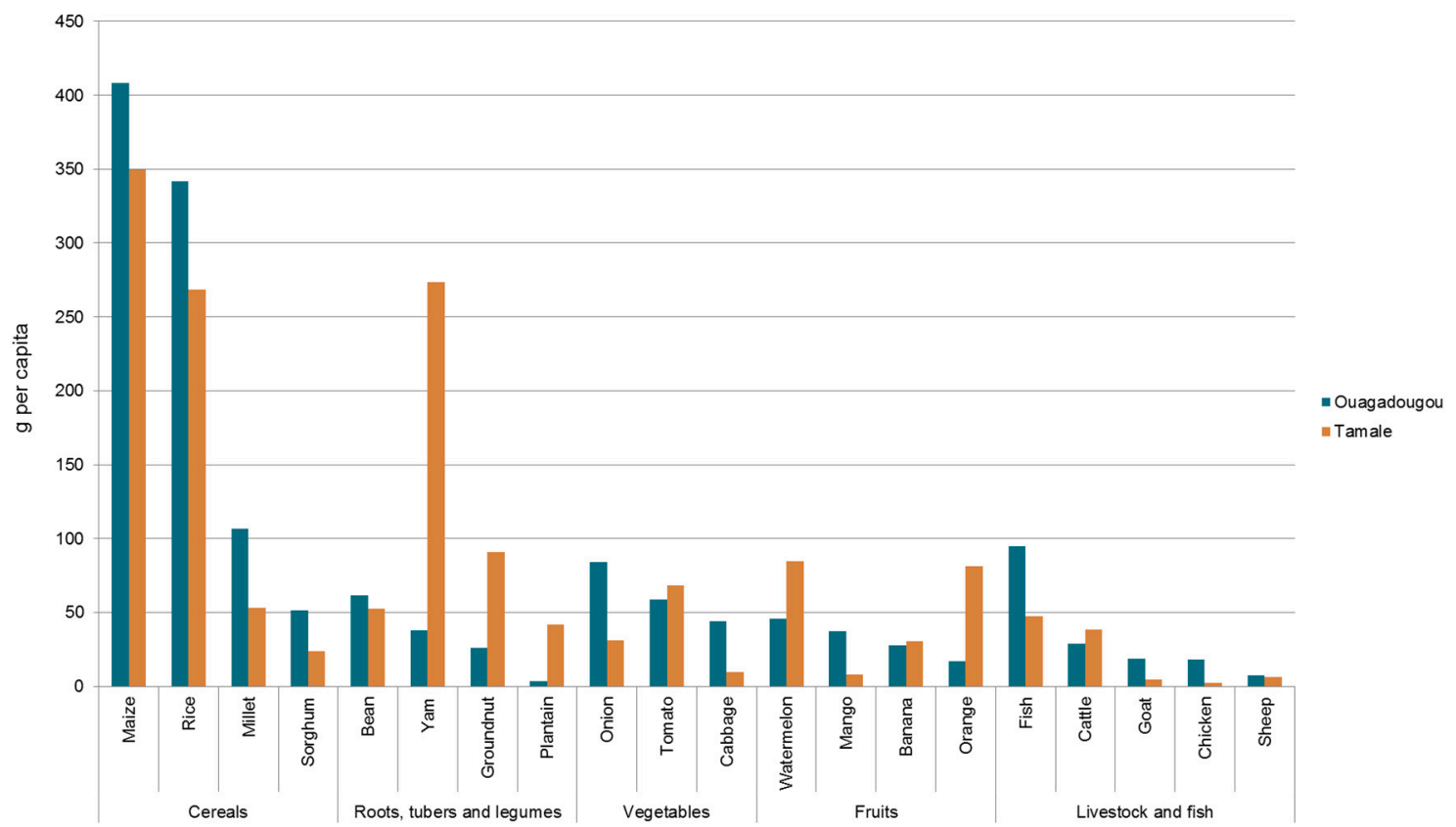

Figure A7. Incoming food quantities in g per capita/day (mean peak- and lean-season values) based on an urban population of 1,475,223 in Ouagadougou (census 2006, [42]) and 371,351 in Tamale (census 2010, [28]).

\section{References}

1. United Nations Human Settlements Programme (UN-Habitat). The State of African Cities 2014: Re-Imagining Sustainable Urban Transitions; United Nations Human Settlements Programme (UN-Habitat): Nairobi, Kenya, 2014.

2. Reardon, T.A. Growing Food for Growing Cities: Transforming Food Systems in an Urbanizing World. 2006. Available online: https://www.thechicagocouncil.org/sites/default/files/report_growingfoodforgrowingcities2. pdf (accessed on 9 November 2016).

3. Peters, C.J.; Bills, N.L.; Wilkins, J.L.; Fick, G.W. Foodshed analysis and its relevance to sustainability. Renew. Agric. Food Syst. 2009, 24, 1-7. [CrossRef]

4. Flora, C.B. Food security in the context of energy and resource depletion: Sustainable agriculture in developing countries. Renew. Agric. Food Syst. 2010, 25, 118-128. [CrossRef]

5. Bellows, A.C.; Hamm, M.W. Local autonomy and sustainable development: Testing import substitution in localizing food systems. Agric. Hum. Values 2001, 18, 271-284. [CrossRef]

6. Feagan, R. The place of food: Mapping out the "local" in local food systems. Prog. Hum. Geogr. 2007, 31, 23-42. [CrossRef]

7. DuPuis, E.M.; Goodman, D. Should we go "home" to eat? Toward a reflexive politics of localism. J. Rural Stud. 2005, 21, 359-371. [CrossRef]

8. Donald, B.; Gertler, M.; Gray, M.; Lobao, L. Re-regionalizing the food system? Camb. J. Reg. Econ. Soc. 2010, 3, 171-175. [CrossRef]

9. ISU (International Sustainability Unit). Food in an Urbanised World: The Role of City Region Food Systems in Resilience and Sustainable Development; ISU (International Sustainability Unit): London, UK, 2015.

10. FAO (Food and Agriculture Organisation of the United Nations). Profitability and Sustainability of Urban and Peri-Urban Agriculture; FAO: Rome, Italy, 2007.

11. Amerasinghe, P.; Bhardwaj, R.M.; Scott, C.; Jella, K.; Marshall, F. Urban Wastewater and Agricultural Reuse Challenges in India; International Water Management Institute: Colombo, Sri Lanka, 2013.

12. Magnusson, U.; Bergmann, K.F. Urban and Peri-Urban Agriculture for Food Security in Low-Income Countries-Challenges and Knowledge Gaps. 2014. Available online: http://www.siani.se/sites/clients. codepositive.com/files/document/slu-global-report-2014-4-urban-and-peri-urban-agriculture-for-foodsecurity-webb.pdf (accessed on 9 November 2016). 
13. Forster, T.; Escudero, A.G. City Regions as Landscapes for People, Food and Nature; EcoAgriculture Partners, on behalf of the Landscapes for People, Food and Nature Initiative: Washington, DC, USA, 2014.

14. Hinrichs, C. The practice and politics of food system localization. J. Rural Stud. 2003, 19, 33-45. [CrossRef]

15. Born, B.; Purcell, M. Avoiding the local trap: Scale and food systems in planning research. J. Plan. Educ. Res. 2006, 26, 195-207. [CrossRef]

16. Battersby, J. The need for a diverse and responsive food system. Urban Agric. Mag. 2014, 27, 10-12.

17. Elbehri, A. Rebuilding West Africa's Food Potential: Policies and Market Incentives for Smallholder-Inclusive Food Value Chains; FAO: Rome, Italy, 2013.

18. Kneafsey, M. The region in food-Important or irrelevant? Camb. J. Reg. Econ. Soc. 2010, 3, 177-190. [CrossRef]

19. Thompson, E.; Harper, A.M.; Kraus, S. Think Globally-Eat Locally: San Francisco Foodshed Assessmen. 2008. Available online: http://www.thegreenhorns.net/wp-content/files_mf/ 1340378421SanFranciscoFoodShedAssessment.pdf (accessed on 9 November 2016).

20. Peters, C.J.; Bills, N.L.; Lembo, A.J.; Wilkins, J.L.; Fick, G.W. Mapping potential foodsheds in New York State: A spatial model for evaluating the capacity to localize food production. Renew. Agric. Food Syst. 2009, 24, 72-84. [CrossRef]

21. Forkes, J. Measuring the Shape and Size of the Foodshed. Ph.D. Thesis, University of Toronto, Toronto, ON, Canada, 2011.

22. Zumkehr, A.; Campbell, J.E. The potential for local croplands to meet US food demand. Front. Ecol. Environ. 2015, 13, 244-248. [CrossRef]

23. Gunasekera, J. Report of the Food Flow Mapping: Kesbewa Urban Area; Janathakshan Guarantee Ltd.: Colombo, Sri Lanka, 2012.

24. Mukui, J.T. Urban and Peri-Urban Agriculture and Rural-to-Urban Food Flows: Case Study of Nairobi: Consultant report prepared for Urban Economy and Finance Branch; United Nations Human Settlements Programme (UN-HABITAT): Nairobi, Kenya, 2002.

25. Drechsel, P.; Graefe, S.; Fink, M. Rural-Urban Food, Nutrient and Virtual Water Flows in Selected West African Cities. 2007. Available online: http://www.iwmi.cgiar.org/Publications/IWMI_Research_Reports/ PDF/PUB115/RR115.pdf (accessed on 9 November 2016).

26. Haggblade, S.; Longabaugh, S.; Boughton, D.; Dembelé, N.; Diallo, B.; Staatz, J.; Tschirley, D. Staple Food Market Sheds in West Africa. MSU International Development Working Paper 121. 2012. Available online: http:/ /fsg.afre.msu.edu/papers/idwp121.pdf (accessed on 9 November 2016).

27. Institut National de la Statistique et de la Démographie. Annuaire statistique 2014; Institut National de la Statistique et de la Démographie: Ouagadougou, Burkina Faso, 2015.

28. Ghana Statistical Service. 2010 Population E Housing Census: National Analytical Report; Ghana Statistical Service: Accra, Ghana, 2013.

29. USAID (United States Agency for International Development). Fact Sheet Burkina Faso: Agriculture and Food Security (Fact Sheet); USAID: Washington, DC, USA, 2015.

30. Ministry of Economy and Finance, Burkina Faso. Investing in Future: Accelerated Growth and Sustainable Development: Business Environment, Investment Opportunities and Public-Private Partnership; Ministry of Economy and Finance, Burkina Faso: Ouagadougou, Burkina Faso, 2011.

31. Chauvin, N.D.; Mulangu, F.; Porto, G. Food Production and Consumption Trends in Sub-Saharan Africa: Prospects for the Transformation of the Agricultural Sector; UNDP, Regional Bureau for Africa: New York, NY, USA, 2012.

32. Bourdet, Y. External Shocks, Exchange Rate Regime and Growth in Burkina Faso and Mali. 2004. Available online: http://www.sida.se/contentassets/022bca5dc1b2482f9ede2ee665124a07/external-shocks-exchangerate-regime-and-growth-in-burkina-faso-and-mali_1417.pdf (accessed on 9 November 2016).

33. Bellwood-Howard, I.; Haring, V.; Karg, H.; Roessler, R.; Schlesinger, J.; Shakya, M. Characteristics of urban and Peri-Urban Agriculture in West Africa: Results of an Exploratory Survey Conducted in Tamale (Ghana) and Ouagadougou (Burkina Faso); International Water Management Institute (IWMI): Colombo, Sri Lanka, 2015.

34. UNDP (United Nations Development Programme). The Ghana Human Development Report 2007: Towards a More Inclusive Society; UNDP: Accra, Ghana, 2007.

35. WFP (World Food Programme). Ghana. 2016. Available online: http://www.wfp.org/node/34673726 (accessed on 2 July 2016). 
36. Auricht, C.; Dixon, J.; Boffa, J.-M.; Garrity, D. Farming Systems of Africa. In Atlas of African Agriculture Research and Development. Revealing Agriculture's Place in Africa; Sebastian, K., Ed.; International Food Policy Research Institute: Washington, DC, USA, 2014; pp. 14-15.

37. Hill, P. Notes on traditional market authority and market periodicity in West Africa. J. Afr. Hist. 1996, 7 , 295-311. [CrossRef]

38. Riemann, D.; Glaser, R.; Kahle, M.; Vogt, S. The CRE tambora.org-New data and tools for collaborative research in climate and environmental history. Geosci. Data J. 2015, 2, 63-77. [CrossRef]

39. Blay-Palmer, A.; Renting, H.; Dubbeling, M. City-Region Food Systems: A Literature Review. 2015. Available online: http://www.ruaf.org/sites/default/files/City\%20Region\%20Food\%20Systems\%20literature\% 20review.pdf (accessed on 9 November 2016).

40. FAO (Food and Agriculture Organization of the United Nations). Program of Food Consumption Surveys; FAO: Rome, Italy, 1964.

41. Ghana Statistical Service. Ghana Living Standards Survey Round 6 (GLSS 6): Main Report; Ghana Statistical Service: Accra, Ghana, 2014.

42. Institut National de la Statistique et de la Démographie. Recensement Général de la Population et de l'habitation de 2006: Résultats Définitifs; Institut National de la Statistique et de la Démographie: Ouagadougou, Burkina Faso, 2008.

43. The World Bank. 2010. Available online: http://datatopics.worldbank.org/consumption (accessed on 15 May 2016).

44. FEWS NET. Burkina Faso Price Bulletin: June 2014. 2014. Available online: http://reliefweb.int/sites/ reliefweb.int/files/resources/Burkina\%20Faso_2014_06_PB_EN.pdf (accessed on 9 November 2016).

45. FAOSTAT. Available online: http://faostat3.fao.org/browse/T/TP/E (accessed on 19 May 2016).

46. Angelucci, F.; Asante-Poku, A.; Anaadumba, P. Analysis of Incentives and Disincentives for Rice in Ghana: Draft Version; (Technical notes series, MAFAP); FAO: Rome, Italy, 2013.

47. FEWS NET. Production and Market Flow Map: Burkina Faso Maize. 2009. Available online: http://www.fews.net/sites/default/files/documents/reports/bf_fullmap_maize_norm.pdf (accessed on 15 June 2016).

48. Terpend, N. An Assessment of Knowledge about Trade and Markets Related to Food Security in West Africa; FAO: Rome, Itlay, 2006.

49. OECD (Organisation for Economic Co-operation and Development). Settlement, Market and Food Security. In West African Futures; OECD Publishing: Paris, France, 2013.

50. Bruyas, C. Road Governance Study: Current Status, Analysis, and Recommendations; Trade Hub Communications: Bethesda, MD, USA, 2014.

51. CILSS (Comité permanent Inter-Etats de Lutte contre la Sécheresse dans le Sahel) and USAID. Road Harassment Report; CILSS, USAID: Ouagadougou, Burkina Faso; Washington, DC, USA, 2013.

52. Teravaninthorn, S.; Raballand, G. Transport Prices and Costs in Africa: A review of the International Corridors; The World Bank: Washington, DC, USA, 2009.

53. FAO (Food and Agriculture Organization of the United Nations). The State of World Fisheries and Aquaculture: Opportunities and Challenges; FAO: Rome, Italy, 2014.

54. Ministry of Food and Agriculture, Ghana. Fish Production, Imports, Exports \& Consumption. 2011. Available online: http://mofa.gov.gh/site/?page_id=2862 (accessed on 15 May 2016).

55. UN Comtrade. 2015. Available online: http://comtrade.un.org/data/ (accessed on 15 May 2016).

56. USAID. West Africa Trade and Investment Hub. Anti-Corruption Campaign Underway with Trade Hub Backing. 2016. Available online: https://www.watradehub.com/en/anti-corruption-campaign-underwaytrade-hub-backing/ (accessed on 15 May 2016).

57. Kamuanga, M.J.B.; Somda, J.; Sanon, Y.; Kagoné, H. Livestock and Regional Market in the Sahel and West Africa: Potentials and Challenges. 2008. Available online: https://www.oecd.org/swac/publications/ 41848366.pdf (accessed on 9 November 2016).

58. Schneider, K.; Gugerty, M.K.; Plotnick, R.; Anderson, C.L. Poultry market in West Africa: Overview \& Comparative Analysis. 2010. Available online: https://evans.uw.edu/sites/default/files/ Evans\%20UW_Request\%2082_Poultry\%20Market\%20Analysis\%20Overview_7-16-2010_0.pdf (accessed on 9 November 2016). 
59. Schneider, K.; Gugerty, M.K.; Plotnick, R. Poultry Market in West Africa: Burkina Faso. 2010. Available online: https://evans.uw.edu/sites/default/files/Evans\%20UW_Request\%2084_Poultry\%20Market\% 20Analysis\%20Burkina\%20Faso_5-28-2010_0.pdf (accessed on 9 November 2016).

60. Ching, L.L.; Edwards, S.; Scialabba, N.E.-H. Climate Change and Food Systems Resilience in sub-Sahara Africa; FAO: Rome, Italy, 2011.

61. Adimabuno, A.M. Marketing and Market Queens: A Case of Tomato Farmers in the Upper East Region of Ghana. Ph.D. Thesis, University of Bonn, Bonn, Germany, 2010. Available online: http:/ hss.ulb.uni-bonn. de/2010/2335/2335.pdf (accessed on 17 December 2014).

62. Amikuzuno, J.; Ihle, R. Seasonal asymmetric price transmission in Ghanaian tomato markets: Adapting Johansen's estimation method. In Proceedings of the Poster presented at the Joint 3rd African Association of Agricultural Economists (AAAE) and 48th Agricultural Economists Association of South Africa (AEASA) Conference, Cape Town, South Africa, 19-23 September 2010.

63. Baba, I.I.Y.; Yirzagla, J.; Mawunya, M. The tomato industry in Ghana-Fundamental challenges, surmounting strategies and perspectives. A review. Int. J. Curr. Res. 2013, 5, 4102-4107.

64. Robinson, E.J.Z.; Kolavalli, S.L. The case of tomato in Ghana: Marketing. 2010. Available online: http://citeseerx. ist.psu.edu/viewdoc/download?doi=10.1.1.222.5285\&rep=rep1\&type=pdf (accessed on 9 November 2016).

65. Moustier, P.; Renting, H. Urban agriculture and short chain food marketing in developing countries. In Cities and Agriculture—Developing Resilient Urban Food Systems; de Zeeuw, H., Drechsel, P., Eds.; Routledge: London, UK, 2015; pp. 121-138.

66. Drechsel, P.; Keraita, B. Irrigated Urban Vegetable Production in Ghana: Characteristics, Benefits and Risk Mitigation; International Water Management Institute (IWMI): Colombo, Sri Lanka, 2014.

67. Karg, H.; Hologa, R.; Schlesinger, J.; Drescher, A.; Glaser, R. Characteristics of the periurban: A multi-method approach applied to Tamale, Ghana. Landsc. Urban Plan. 2016, submitted.

68. McKim, W. The periodic market system in Northeastern Ghana. Econ. Geogr. 1972, 48, 333-344. [CrossRef]

69. Drechsel, P.; Karg, H.; Appoh, R.K.; Akoto-Danso, E.K. Resilience of Rural-Urban Food Flows in West Africa. In Proceedings of the International conference on Agri-Chains and Sustainable Development: Linking Local and Global Dynamics, Montpellier, France, 12-14 December 2016.

70. Drechsel, P.; Karg, H.; Amoah, P. Food flows and waste: Planning for the dirty side of urban food security. In Integrating Food into Urban Planning; UCL Press: London, UK, 2016, submitted.

71. IRIN (Integrated Regional Information Networks). 2007. Available online: http://reliefweb.int/report/ ghana/ghana-food-shortages-follow-drought-floods (accessed on 8 June 2016).

72. Tendall, D.M.; Joerin, J.; Kopainsky, B.; Edwards, P.; Shreck, A.; Le, Q.B.; Kruetli, P.; Grant, M.; Six, J. Food system resilience: Defining the concept. Glob. Food Secur. 2015, 6, 17-23. [CrossRef] 